\title{
SISTEMA CLASSIFICATÓRIO APLICADO ÀS BACIAS SEDIMENTARES BRASILEIRAS *
}

\author{
ANTONIO MANUEL F. DE FIGUEIREDO** e GUILHERME P. RAJA GABAGLIA***
}

\begin{abstract}
Several types of sedimentary basin classifications have been proposed all around the world, before and after the onset of the Plate Tectonic Theory, and some of them were applied to the Brazilian basins, principally Klemme's classification. In 1983, Exxon geologists Kingston, Dishioon and Williams published their Global Basin Classification System where to each basin a formula was atributed, reflecting its tectonic and sedimentary evolution. The components of this formula are coded by letters and numbers representing stages of forming tectonics, modifying tectonics and also the sedimentary package that fills up the basins. Therefore, this classification system, in contrast with previous ones, allows a fast evaluation of the petroleum potencial of sedimentary basins, as well as the characterization of fundamental differences among them. Some of the most representative Brazilian petroleum-bearing basins are discussed in details in this paper using the Kingston's classification system. Also a general picture of the in situ hydrocarbons volumes, discovered in the Brazilian basins, is displayed according to this classification. These data are compared with the published ones by Kingston and co-workers based upon 800 basins of the world.
\end{abstract}

INTRODUÇÃO Neste artigo, sumarizam-se os resultados do trabalho efetuado por um grupo de geólogos da Petróleo Brasileiro S.A. (Petrobrás), especialmente selecionados para analisar as bacias brasileiras, visando classificá-las e compará-las de acordo com os mais modernos métodos aceitos pela comunidade geológica, adotando-se principalmente a proposta de Kingston et al. (1983a e 1983b).

\section{EVOLUCCÃO DOS CONCEITOS ACERCA DAS CLASSIFI. CAÇÕES DAS BACIAS SEDIMENTARES Cerca de} 800 bacias ou províncias sedimentares estão presentes na superfície do globo terrestre, das quais mais de 600 são razoavelmente conhecidas quanto a seu arcabouço estrutural-estratigráfico (Fig. 1).

Desde os primórdios do estudo das bacias sedimentares sentiu-se a necessidade de ordenar este conhecimento, caracterizando e definindo diversas categonas de bacias, seja com interesse académico, seja sob o ponto de vista econômico. As primeiras classificações, do fim do século passado e da primeira metade deste século, possuram enfoque puramente descritivo, suportadas em sua gênese pela aplicação da Teoria Geossinclinal, amplamente aceita até cerca de 20 anos atrás. Importantes avanços nas ciências geológicas, a partir do estudo do assoalho oceânico das planíceis abissais, permitiram o estabelecimento, nos anos 60 , da teoria unificadora da Tectônica de Placas. 0 importante papel, no mundo atual, do petróleo e de outros recursos minerais, presentes em várias escalas de abundância nas bacias sedimentares, conduziu a um considerável incremento na compreensão da origem e da evolução dessas bacias, o que permitiu a elaboração de várias classificações aprimoradas ao longo dos últimos 15 anos.

A primeira tentativa de situar as áreas contendo rochas sedimentares em um contexto unitário foi elaborada por Hall, em 1859, estudando as rochas dos Apalaches, EUA, e criando o conceito de geossinclinal (termo descritivo que se refere ao local onde é depositado grande volume ou espes- sura de sedimentos). Este geólogo considerava que o próprio peso da coluna sedimentar era responsável pela contínua subsidência da área (geossinclinal) onde os sedimentos se acumulavam.

Em 1866, o geólogo Dana utilizou este mesmo conceito e associou-o às margens continentais, as quais considerou como bacias sedimentares resultantes de esforcos crustais tangenciais ligados ao resfriamento e à contração da Terra.

Lançavam-se, portanto, as bases da Teoria Geossinclinal, que seria posteriormente aperfeiçoada e ampliada por Stille (1940, apud Loczy \& Ladeira 1976). O quadro $1 A$ mostra a proposta de subdivisão dos geossinclinais feita por este autor. Estes elementos estão descritos com grande detalhe nos clássicos trabalhos de Auboin (1961, 1965, apud Loczy \& Ladeira 1976) sobre a Teoria Geossinclinal.

Tais subdivisões das bacias sedimentares foram aceitas pela maioria dos geólogos da época e serviram de sustentáculo para classificações mais elaboradas. Deste modo, Kay (1947) reafirmou a terminologia definida por Stille (1940), mantendo os termos "eugeossinclinal" e "miogeossinclinal". Subdividiu, entretanto, os parageossinclinais (que correspondem àqueles das zonas cratônicas de Stille) em vários tipos, conforme mostra o quadro $1 B$. Esta classificação serviu de base para as primeiras tentativas de classificação de bacias por pesquisadores ligados à indústria do petróleo.

Assim, Weeks (1952), no célebre trabalho Factors of Sedimentary Basin Development that Control Oil Occurrence, estabeleceu que a existência de petróleo em bacias sedimentares dependeria de dois fatores básicos: $a$. tipo genético e arquitetura da bacia; e $b$. condiçōes primárias, no substrato da bacia deposicional. 0 critério básico da classificação (Quadro 1C) então proposta por Weeks (op cit.) foi o enquadramento das bacias em função da posição das mesmas em relação aos cinturões móveis lineares e às áreas estáveis (rígidas) da litosfera. Neste trabalho, o autor concluiu que não existe um simples fator ou indicador (yardstick) para explicar a incidência de hidrocarbonetos;

\footnotetext{
* Trabalho apresentado como conferência ao XXXIV Congresso Brasileiro de Geologia em Goiânia, GO, em oùtubro de 1986

* * Petrobrás, Departamento de Exploração (Depex). Av. Chile, 65, sala 1356, CEP 20035, Rio de Janeiro, RJ, Brasil

*** Petrobrás, Centro de Pesquisas e Desenvolvimento Leopoldo A. Miguez de Mello (Cenpes). Pç. Mahatma Gandhi, 14, sala 603, CEP 20031, Rio de Janeiro, RJ, Brasil
} 


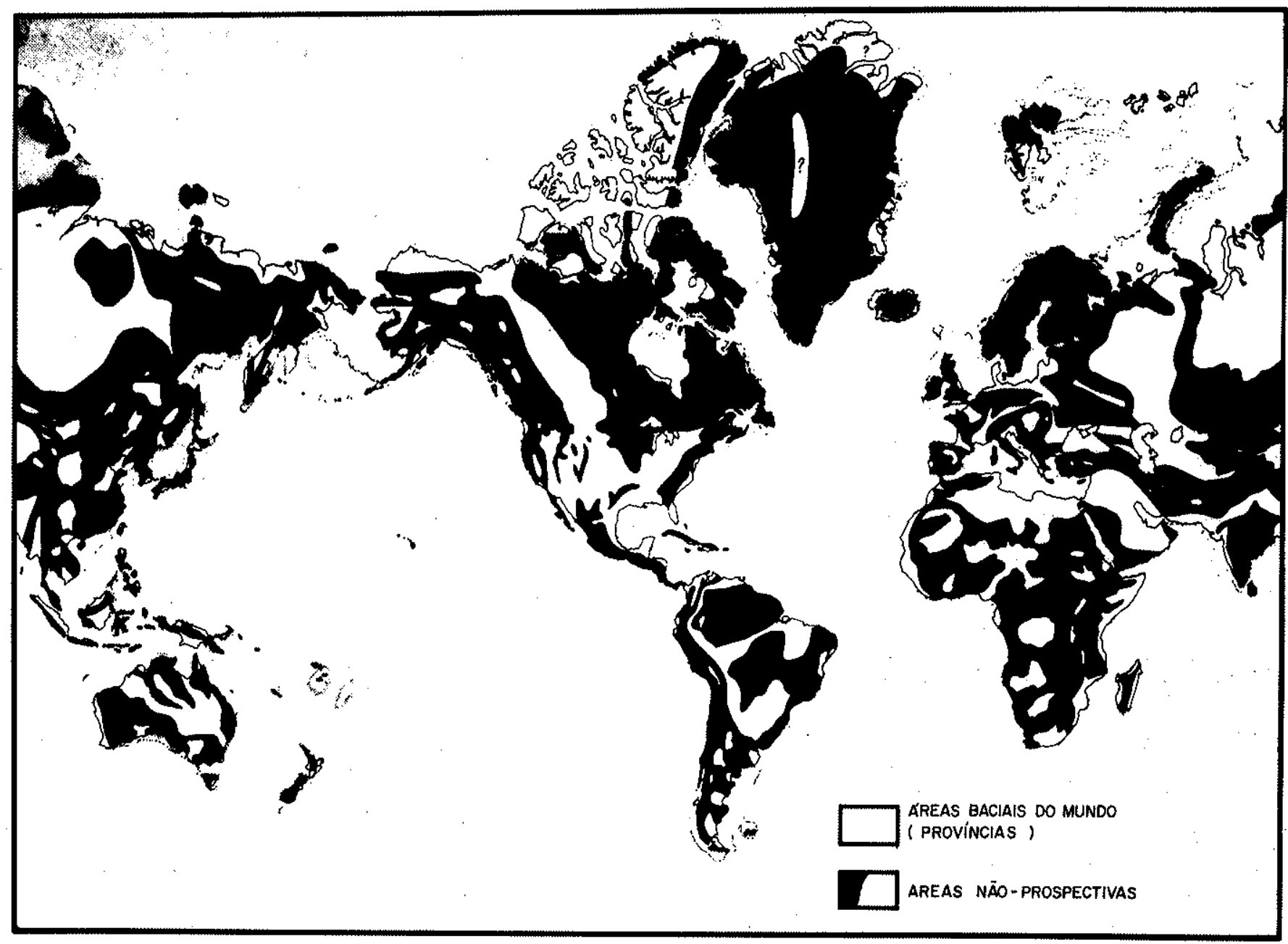

Figura 1 - Areas sedimentares do mundo (segundo Klemme 1980)

cuja variação está relacionada, primordialmente, à arquitetura da bacia e ao ambiente deposicional que nela se desenvolve.

King (1959) e Uspenskaya (1967) também contribuíram com a elaboração de novas classificações. Com o desenvolvimento da teoria unificadora da Tectônica de Placas, autores como Mitchell \& Reading (1969) já consideravam as bacias sedimentares e as margens continentais à luz da separação das placas litosféricas, da criação da crosta oceânica e da existência de zonas de subdução e de arcos de ilhas.

Dewey \& Bird, em 1970, concluíram que a classificação de Kay (1947), com consideráveis modificações e acréscimos, poderia ser utilizada sob o novo enfoque da Tectônica Global. Esta classificação, mostrada no quadro $I D$, foi engendrada mais para definir os estágios de formação das bacias ou geossinclinais do que para mostrar o produto final da evolução do processo.

Klemme (1970, apud Halbouty et al. 1970), com base na Tectônica de Placas, mas influenciado pelas idéias de Weeks, Uspenskaya e Kay, elaborou uma classificação de ampla aceitação na indústria do petróleo utilizando os se guintes critérios fundamentais: tipo de crosta; posição geo- tectônica da bacia em relação aos limites da placa; forma e idade da bacia; presença de um ou mais ciclos deposicionais; e elementos associados à ocorrência de hidrocarbonetos. Tendo em vista a importância desta classificação ao longo dos anos 70 e início dos anos 80 , por sua utilização em conjunção com a distribuição mundial dos campos gigantes de petróleo e do estudo estatístico de ocorrência de hidrocarbonetos em cada classe de bacia (Quadro 2), ela será apresentada com maior detalhe. Observe-se que na época, devido às dificuldades tecnológicas para a efe tiva exploração e explotação de hidrocarbonetos em bacias sobre crosta oceânica (águas profundas), estas não foram consideradas por Klemme.

Foram assim definidos por Klemme (1970, 1971, 1975, 1980) oito tipos de bacia (Fig. 2), os quais são discutidos a seguir:

- Bacias do Tipo I (Interior Cratônico) - Jazem no interior das áreas cratônicas pré-cambrianas e têm fundo chato. Săo preenchidas por depósitos de plataforma rasa (arenitos, folhelhos, carbonatos e evaporitos) e sua gênese ainda é bastante discutida. Especula-se a existência de um rifte inicial ou de um hot spot com a introdução de material mais denso 


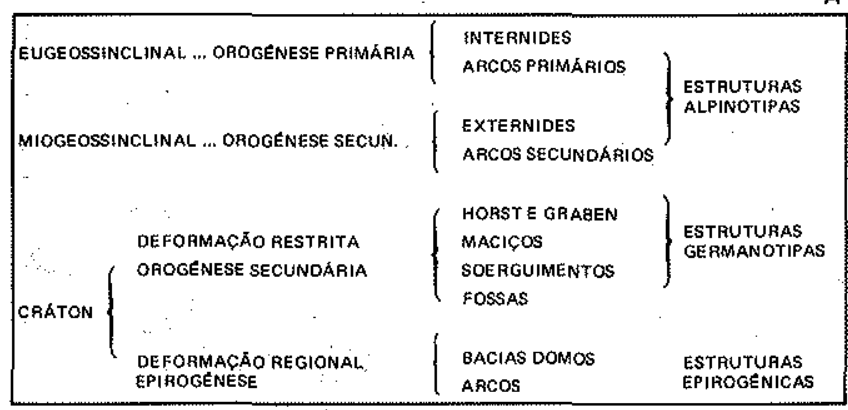

1 - ORTOGEOSSINCLINAIS:

A. EUGEOSSINCLINAIS

II - POS-ORTOGEOSSINCLINAIS

A EPITEOSSINCLINAIS: SOBRE OEUGEOSSINCLINAL

C - PARALLOGEOSSINCLINAIS: GEOSSINCLINAIS COSTEIRAS

III - GEOSSINCLINAIS INTHACONTINENTAIS:

A - EXOGEOSSINCLINAIS: GEOSSINCLINAIS ADIACENTES

C - ZEUGOGEOSS INCLIINAIS: GEOSSINCLINAIS EM "YOKEO" (ZONA DEPRIMIDA ENTRE DOI ALTOSI

$\mathrm{C}$

\begin{tabular}{|c|c|c|}
\hline GRUPO & & CL.ASSE E SUB.CLASSE \\
\hline \multirow{5}{*}{$\begin{array}{l}\text { CINTUARO } \\
\text { MOVEL }\end{array}$} & \multirow{2}{*}{$\begin{array}{l}\text { MARGINAL } \\
\text { (EXTRACONTINENTAL) }\end{array}$} & MARGINAL ABERTA \\
\hline & & MARGINAL FECHADA \\
\hline & & \multirow{3}{*}{$\begin{array}{l}\text { INTRACONTINENTAL } \\
\text { BACIAS DE SEGUNDA OADEM DESENVOLVIDAS } \\
\text { NAS ZONAS MONTANHOSAS DOS CINTUROES } \\
\text { MOVEIS }\end{array}$} \\
\hline & INTERMONTANA & \\
\hline & MEDIANA & \\
\hline \multirow{5}{*}{$\begin{array}{l}\text { REGIOES } \\
\text { ESTAVEIS }\end{array}$} & \multicolumn{2}{|r|}{ PLATAFORMA DE ANTEPAIS } \\
\hline & \multicolumn{2}{|r|}{ INTERIOA PAOXIMO } \\
\hline & \multicolumn{2}{|r|}{ INTERIOR REMOTO. } \\
\hline & \multicolumn{2}{|r|}{ GRABEN OU MEIO-GRABEN } \\
\hline & \multicolumn{2}{|r|}{ COSTEIRA ESTAVEL } \\
\hline
\end{tabular}

D

\begin{tabular}{|c|c|c|c|}
\hline \multicolumn{3}{|r|}{ TERMINOLOGIA } & INTERPGETACAO \\
\hline \multicolumn{3}{|c|}{ AUTOGEOSSINCLLINEO } & BACIA INTRACRATONICA NAOOLINEAR \\
\hline \multirow{8}{*}{ 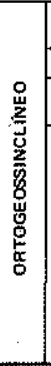 } & \multicolumn{2}{|r|}{ EPIEUGEOSSINCLINEO } & $\begin{array}{l}\text { FOSSA LIMITADA POR FAL.HAS FORMADA } \\
\text { DURANTE A DISTENSĀO CONTINENTAL }\end{array}$ \\
\hline & \multicolumn{2}{|r|}{ MIOGEOSSINCLINEO } & FOSSA AOJACENTE A MARGEM CONTINENTAL \\
\hline & \multicolumn{2}{|r|}{ MIOGEOCEINEO } & $\begin{array}{l}\text { CUNHA QUE SE ESPESSA EM DIRECAOO AO } \\
\text { OCEANO, ADJACENTE A MARGEM CONTINENTAL }\end{array}$ \\
\hline & \multirow{5}{*}{ 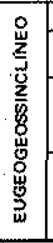 } & EPIEUGEOSSINCLINNEO & COMO ACIMA I = TAF ROGEOSSINCLINEO) \\
\hline & & PARALIOGEOOSSINCLINEO & $\begin{array}{l}\text { CUNHA ESPESSA CONSTRUIDA A PARTIR } \\
\text { DA MARGEM CONTINENTAL }\end{array}$ \\
\hline & & \multirow[b]{2}{*}{ LEPTOGEOSSINCLINEO } & SOPE CONTINENTAL FAMINTO \\
\hline & & & $\begin{array}{l}\text { PLANICIE OCEANICA ABISSAL E CADEIA } \\
\text { MESO-OCE ANICA E MONTES SUBMARINOS } \\
\end{array}$ \\
\hline & & KINEGEOCLIINEO & $\begin{array}{l}\text { FOSSA DE CONTRACEO OU COMPLEXO OE FOSSA } \\
\text { LOCALIZADA ENTRE A MARGEM CONTINENTAL } \\
\text { EAOROGENIA ORTOTECTONICA EM DESENVOL. } \\
\text { VIMENTO }\end{array}$ \\
\hline \multicolumn{3}{|r|}{ EXOGEOSSINCLINEO } & $\begin{array}{l}\text { FOSSA OU COMPLEXO OE FOSSAS OESENVOL. } \\
\text { VIOO NO LOCAL OE UM MIOGEOSSINCLINEO OU } \\
\text { MOOGEOLIÍNEO MAIS ANTIGO }\end{array}$ \\
\hline \multicolumn{3}{|c|}{ ZEUGOGEOSSINCLINEO } & $\begin{array}{l}\text { FOSSA LIMITADA POR FALHAS, SITUADA EM } \\
\text { ZONA OROGENICA ORTOTECTONICA }\end{array}$ \\
\hline \multirow{6}{*}{ 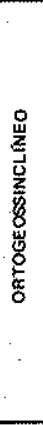 } & \multirow{6}{*}{ 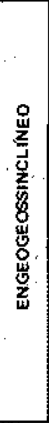 } & IDIOGEOSSINCLÍNEO & $\begin{array}{l}\text { PEQUENA BACIA OCEANICA ESTATICA, SITUADA } \\
\text { ENTRE A MARGEM CONTINENTAL } 8 \text { OARCO } \\
\text { DE ILHAS. } \\
\text { PEOUENA BACIA OCEANICA DE CONTRACAOAO } \\
\text { SITUADA ENTRE ARCOS.DE-ULHA }\end{array}$ \\
\hline & & ARCODE ILHAS. & $\begin{array}{l}\text { OROGENESE OATOTTECTONICA ENZIMATICA } \\
\text { DESENVOLVIDA PELO DESLOCAMENTO HORI. } \\
\text { ZONTAL E EMPILHAMENTO OE SEDIMENTOS } \\
\text { OCEANICOSE VULCANICOS, COM DEFORMACAO } \\
\text { E METAMORFISMO }\end{array}$ \\
\hline & & FOSSA OCEANICA & LOCALIZADA NA ZONA DE CONSUMO OE PLACAS \\
\hline & & LEPTOGEOSSINCLINEO & $\begin{array}{l}\text { PLANICIE ABISSAL OCEANICA, CADEIA } \\
\text { MESO.OCEANICA MONTES SUBMARINOS }\end{array}$ \\
\hline & & \multirow{2}{*}{$\begin{array}{c}\text { PEQUENA BACIA } \\
\text { OCEANICA }\end{array}$} & $\begin{array}{l}\text { OCEANO EM ESTAGIO FINAL DE CONTRACCAO } \\
\text { POR CONSUMO DE PLACAS EM MARGENS EM } \\
\text { COLISÄO }\end{array}$ \\
\hline & & & $\begin{array}{l}\text { OCEANO EM ESTAGIO FINAL DE CONTAACAO } \\
\text { POR CONSUMO DE PLACAS ENVOLVENDO UMA } \\
\text { UNICA MAAGEM }\end{array}$ \\
\hline \multicolumn{3}{|r|}{ EXOGEOSSINCLINEO } & FOSSAEXTERIOR \\
\hline
\end{tabular}

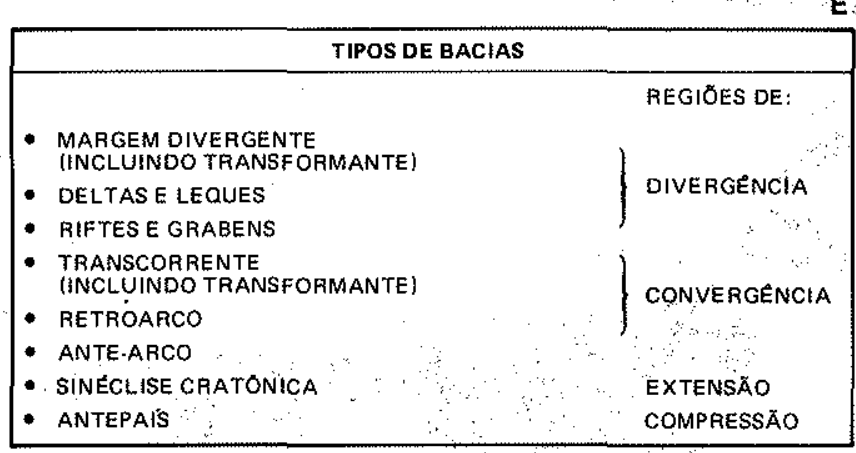

E.

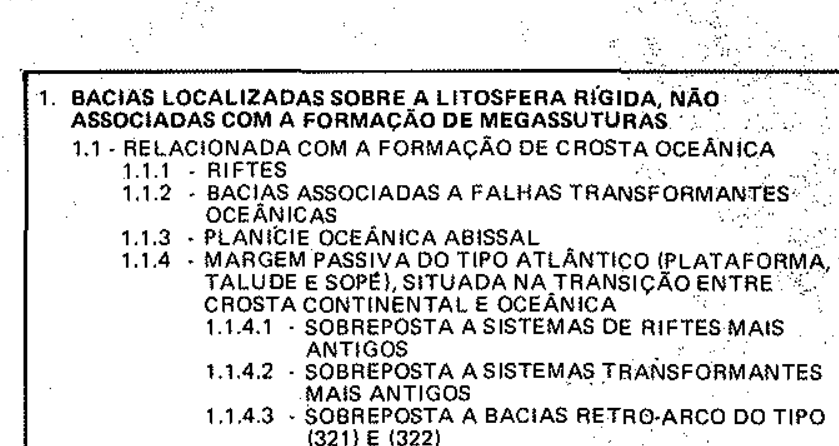

1.2 - LOCALIZADA SOBRE LITOSFERA CONTINENTAL

PRË-MESOZOICA
1.2 .1 - BACIAS CRATONICAS

1.2.1.1 - LOCALIZADA SOBRE GRABENS MAIS ANTIGOS 1.2 .1 .1 - LOCALIZADA SOBRE GRABENS MAIS ANTIGOS
1.2 .1 .2 - LOCALIIZADA SOBRE BACIAS RETRO-ARCO DO
TIPO (322) MAIS ANTIGAS:

2. BACIAS PERISSUTURAIS SOBRE A LITOSFERA RIGIDA, ASSOCIADAS

COM A FORMAC ĀO DE MEGASSUTURA COMPRESSIONAL

2.1. FOSSA MARINHA SOBRE CROSTA OCEĀNICA ADJACENTE A MARGEM DE SUBDUCÇÃOODO TIPO B

2.2 - ANTEFOSSA E SEDIMEN TOS PLATAFORMAIS SOTOPOSTOS, SOBRE CROSTA CONTINENTAL. ADJACENTE A MARGEM DE SUBDUCÇAO DO TIPO A

2.2.1 - RAMPA COM GRABENS SOTERRADOS, COM PEQUENO OU NENHUM FAL HAMENTO

2.2.2 - DOMINADAS POR FALHAMENTO

2.3 - BACIAS "TIPO CHINES" ASSOCIADAS COM FALHAMENTO DISTAL, RELACIONADAS A MEGASSUTURA COMPRESSIONAL,

3. BACIAS EPISSUTURAIS LOCALIZADAS E, EM SUA MAIOR PARTE, CONTIDAS EM MEGASSUTURA COMPRESSIONAI

3.1. ASSOCIADAS COM ZONA OE SUBDUCCÃO DO TIPO B 3.1.1. - BACIAS ANTE.ARCO

3.12 . BACIAS RETRO-ARCO CIRCUMPACÍFICAS

3.1.2.1 - BACIAS RETRO.ARCO SOBRE CROSTA OCE ANICA E ASSOCIADAS COM SUBDUCÇÃO DO TIPO B (MARGINAL STRICTO SENSU)

3.1.2.2 - BACIAS RETRO.ARCO SOBRE CROSTA CONTINENTAL OU INTERMEDIARIA,

3.2 - BACIAS RETRO-ARCO, ASSOCIADAS COM.COLISÃO CONTINENTAL E SOBRE O LADO CONCAVO DO ARCO DE SUBDUCCÃO DO TIPO A

3.2.1 - SOBRE CROSTA CONTINENTAL OU BACIAS TIPO

3.2.2 POBRE CROSTA TRANSICIONAL E OCEÃNICA OU BACIAS

3.3 - BACIAS RELACIONADAS A SISTEMAS DE MAGACISALHAMENTO EPISSUTURAIS

3.3.1 - BACIA TIPO GREAT BASIN

3.3.2 - BACIA TIPO CALIFORNIA

F

Quadro 1 - Classificações propostas para as bacias sedimentares, segundo os seguintes autores: A. Stille (1940); B. Kay (1947), C. Weeks (1952); D.Dewey \& Bird (1970; E. Huff (1978); F. Bally \& Snelson (1980); e G. Perrodon (1983)

1. CENÁRIO INTRAPLAGA

1.1 - RIFTES CONTINENTAIS

1.2. BACIAS DE PLATAFORMA

1.3- BACIAS DE MARGEM PASSIVA

2. CENARIO EM FRONTEIRA DE PLACA

2.1. BACIAS DE ZONAS TRANSFORMANTES

2.2 - BACIAS DE ZONAS DE SUBDUCCAAO E DE COLISÄO 2.2.1 - BACIAS DE ARCO INSULAR

2.1

2.2.3 ALGUNS EXEMPLOS DE BACIAS COMPLEXAS

G 


\begin{tabular}{|c|c|c|c|c|c|c|c|c|}
\hline Tipo da crosta & \multicolumn{3}{|c|}{ Cratônica } & \multicolumn{5}{|c|}{ Intermediária } \\
\hline $\begin{array}{l}\text { Dados } \\
\text { estatísticos Tipo de bacia }\end{array}$ & Tipo I & Tipo II & Tipo III & Tipo IV & Tipo V & Tipo VI & Tipo VII & Tipo VIII \\
\hline $\begin{array}{l}\text { Reservas totais } \\
\text { (em } 10^{9} \text { barris) }\end{array}$ & 0,67 & 240,0 & 50,0 & 450,0 & 1,7 & 54,0 & 12,0 & 8,0 \\
\hline $\begin{array}{l}\text { N. }{ }^{\circ} \text { de baclas com } \\
\text { campos gigantes }\end{array}$ & 1 & 22 & 9 & 10 & 1 & 6 & 5 & 2 \\
\hline $\begin{array}{l}\mathrm{N} \cdot{ }^{\circ} \text { de campos } \\
\text { gigantes }\end{array}$ & 1 & 89 & 36 & 90 & 2 & 23 & 11 & 9 \\
\hline $\begin{array}{l}\text { Recuperacão } \\
\text { estimada dé bleo ou } \\
\text { gás (BBL por milha } \\
\text { de sedimento) }\end{array}$ & 35.000 & 100.000 & 140.000 & 200.000 & 18.000 & 250.000 & 150.000 & 200.000 \\
\hline $\begin{array}{l}\text { Reservas para tipo } \\
\text { reservatório }\left(10^{9} \mathrm{BBL}\right)\end{array}$ & & & & & & & & \\
\hline $\begin{array}{l}\text { Arenitos } \\
\text { Carbonatos }\end{array}$ & $\begin{array}{l}0,34 \\
0,33\end{array}$ & $\begin{array}{r}195,0 \\
45,0\end{array}$ & $\begin{array}{l}31,5 \\
18,5\end{array}$ & $\begin{array}{l}200,0 \\
250,0\end{array}$ & $\begin{array}{c}1,7 \\
?\end{array}$ & 54,0 & 12,0 & $\begin{array}{l}8,0 \text { Ar. } 61 \% \\
\text { Car. } 39 \%\end{array}$ \\
\hline $\begin{array}{l}\text { Idade das reservas } \\
\text { Terclárlo } \\
\text { Mesozólco } \\
\text { Paleozólco }\end{array}$ & 0,67 & $\begin{array}{r}7,0 \\
43,0 \\
90,0\end{array}$ & $\begin{array}{r}12,0 \\
30,0 \\
8,0\end{array}$ & $\begin{array}{r}80,0 \\
365,0 \\
\quad 5,0\end{array}$ & $\begin{array}{l}1,1 \\
0,6\end{array}$ & 54,0 & 12,0 & $\begin{array}{r}8,0 \quad 174=23 \% \\
538=65 \% \\
104=12 \%\end{array}$ \\
\hline $\begin{array}{l}\text { Tipos de trapas } \\
\text { estruturais }\end{array}$ & $\begin{array}{l}\text { Arcos } \\
\text { Regionals } \\
\cdots\end{array}$ & $\begin{array}{l}\text { Arcos } \\
\text { Regionais } \\
\text { e Recifes }\end{array}$ & $\begin{array}{l}\text { Blocos } \\
\text { Basculados } \\
\text { O Recifes }\end{array}$ & $\begin{array}{l}\text { Grandes } \\
\text { Anticlinals } \\
\text { e Blocos } \\
\text { Falhados }\end{array}$ & $\begin{array}{l}\text { Blocos } \\
\text { Falhados } \\
\text { Associados } \\
\text { a Variações } \\
\text { Estratigrăf. }\end{array}$ & $\begin{array}{l}\text { Anticlinals } \\
\text { e Blocos } \\
\text { Falhados }\end{array}$ & $\begin{array}{c}\text { Dobras } \\
\text { Falhadas } \\
\text { Associadas } \\
\text { a Variaçōes } \\
\text { Estratigrdf. }\end{array}$ & $\begin{array}{l}\text { Estrutura } \\
\text { de Fluxo } \\
\text { Anticlinais } \\
\text { de } \\
\text { Rollover }\end{array}$ \\
\hline
\end{tabular}

Quadro 2 - Classificação proposta por Klemme (1970), em associação com dados estatísticos referentes à ocorrência de hidrocarbonetos em cada tipo de bacia

na crosta, que criaria condições para o desenvolvimento de uma sinéclise no interior do cráton. A Bacia de Illinois exemplifica este tipo.

- Bacias do Tipo II (Intracontinental Composto) - Estão localizadas nas margens ativas dos crátons, ou em suas proximidades, variando em tamanho de miogeossinclinais subcontinentais a pequenas bacias intermontanas. Do mesmo modo que as bacias interiores, estas bacias multicíclicas têm usualmente um ciclo inicial de sedimentos paleozóicos de plataforma. Em algumas delas este ciclo foi tectonizado pe. los movimentos da orogenia herciniaria. Esta sequiência é seguida pela deposição de sedimentos terrígenos de segundo ciclo do Paleozóico Tardio ou do Mesozóico. O tipo $2 \mathrm{~A}$ (complexa), definido por Klemme em 1980, é formado por bacias geralmente multicíclicas, localizadas nas áreas externas dos crátons, apresentando perfil assimétrico irregular de forma elíptica. Sua gênese parece estar relacionada a rifteamento múltiplo recoberto por uma sinéclise bastante simétrica, que relembra o Tipo I anteriormente descrito. Exemplos destes tipos são as bacias de Alberta (2) e do Mar do Norte $(2 A)$.

- Bacias do Tipo III (Rifte) -É um tipo de bacia cratônica que pode também representar uma área de espalhamento de assoalho oceânico incipiente, que permaneceu inativo. Estas bacias são de tamanho médio a pequeno, lineares e falhadas. Este tipo parece ser de fundamental importância na geração das bacias sedimentares, podendo ocorrer em vários estágios do desenvolvimento de quase todos os tipos de bacias. Exemplos típicos de bacias rifte são o Golfo de Suez, a Bacia de Sirte e a do Recôncavo.
- Bacias do Tipo IV (Extracontinental) - Este tipo de bacia, implantada em crosta intermediária, está associado com pequenas bacias oceânicas. Algumas se estendem costa afora, como é o caso de bacias do Oriente Médio e da Venezuela (4A); outras são abertas e parecem simplesmente submergir em direção ao mar $(4 C)$, como é o caso da Costa do Golfo, North Slope etc. Outras, ainda, são freqüentemente chamadas de antefossa e estão presentes ao longo de estreitas porções do Tethys, tais como a Molasse Trough e a Bacia do Indus $(4 B)$. Bacias do Tipo $4 C$ podem transformar-se em Tipo $4 A$ como resultado da colisão de placas continentais. A continuação desta colisão pode destruir grande parte da bacia Tipo $4 A$, deixando somente uma bacia do Tipo $4 B$

- Bacias do Tipo V. Este tipo de bacia pode corresponder à fase final das bacias do Tipo III (rifte), que foram separadas por distâncias oceânicas. Estas bacias foram chamadas pelo autor de pull-apart, termo hoje mais utilizado pela comunidade geológica para designar bacias originadas em áreas onde ocorre o deslizamento lateral de placas litosféricas. Elas estão localizadas em ambos os lados dos oceanos Atlântico e Índico, sendo difícil determinar a taxa de espalhamento e a época de sua passagem para o Tipo V. São bacias lineares, com falhamentos down to sea, ocorrendo ao longo da costa. Acredita-se que sua gênese esteja ligada à presença de um estágio inicial rifte, ao qual se segue a introdução de material básico, com a formação de um eixo de espalhamento de fundo oceânico. Especula-se que a subsidência deste tipo de bacia seria causada tanto pelo resfriamento termal do material básico introduzido (mais denso), quanto pelo 


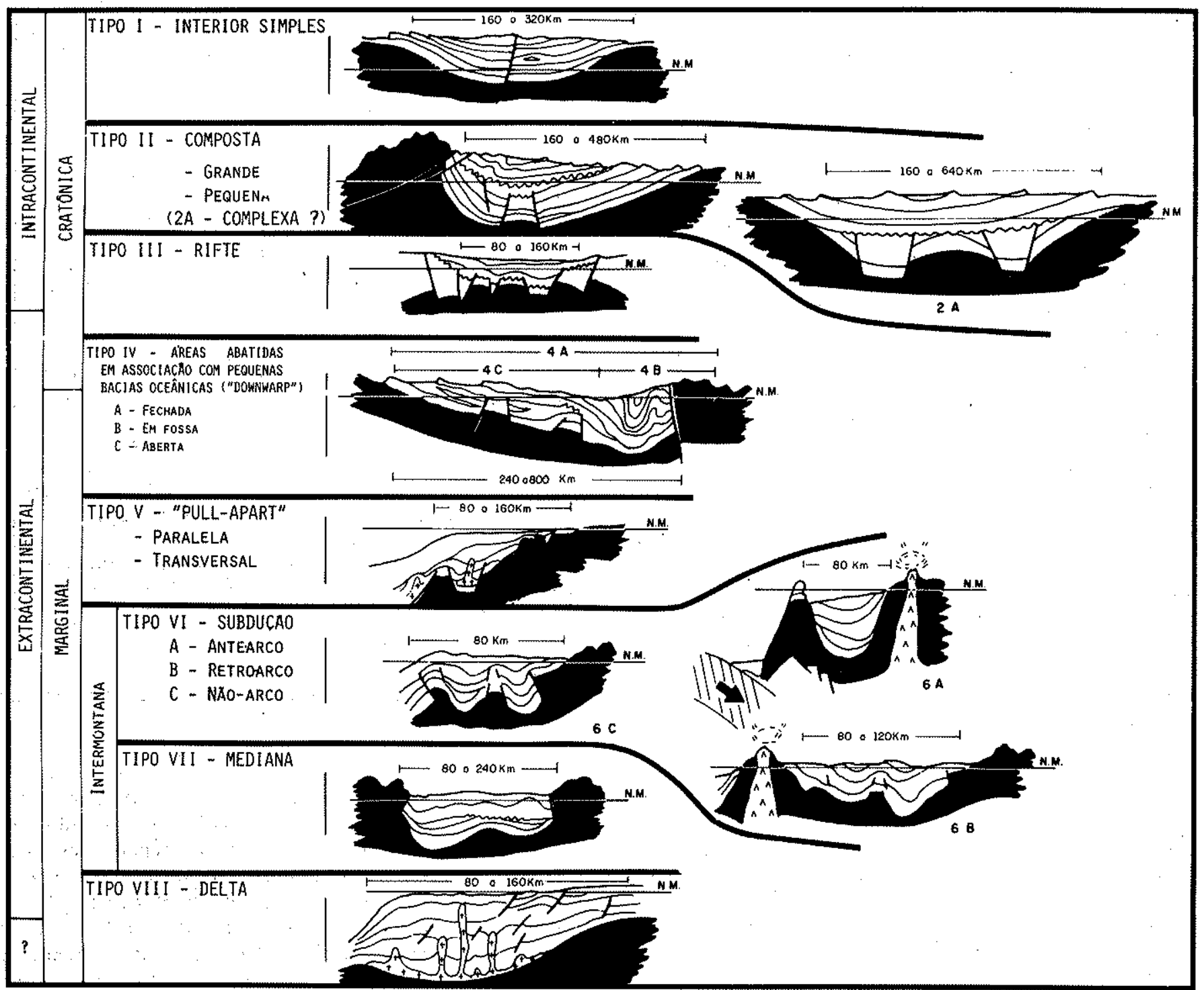

Figura 2 - Classificação de Klemme (1980)

próprio peso de sedimentos fornecidos pela massa continental adjacente. As bacias de Campos e Cabinda-Angola são exemplos típicos.

Os dados da margem atlântica, conforme já salientaram Asmus \& Porto (1972), indicam que dentro desta classe pelo menos dois subtipos de bacias podem ser definidos. Um corresponde ao subtipo paralelo, no qual ocorre extensa deposição de sal durante os estágios intermediários de desenvolvimento. Deste modo, sal mesozóico é encontrado nas bacias costeiras do Canadá, Estados Uniđos da América, Brasil, África e Europa. O outro tipo parece ter sido formado pela movimentação leste-oeste de segmentos transformantes durante o rompimento do continente gonduânico, resultando, por exemplo, na formação de bacias entre o norte do Brasil e Libéria e Daomé. Este tipo parece não conter grandes depósitos de sal e freqüentemente mostra arcabouço tectônico diferente, nos quais esforços compressionais ou transpressionais se constituem igualmente em importantes elementos.

- Bacias do Tipo VI - Ocorrem paralelamente às zonas de subdução, entre o continente e as bacias oceânicas. São de pequeno tamanho, principalmente terciárias de segundo ciclo, e estão localizadas tanto transversalmente como seguindo o strike de antigos eugeossinclinais deformados. Podem ser subdivididas em três subtipos relacionados à existência de arcos-de-ilhas $(6 \mathrm{~A}$ ante-arco, $6 \mathrm{~B}$ retro-arco e $6 \mathrm{C}$ não-arco) e sua gênese está diretamente ligada à evolução das zonas de subdução. As bacias de Talara, Sumatra e Los Angeles são representativas desta classe.

- Bacias do Tipo VII - Desenvolvem-se em áreas montanhosas originadas por esforços compressionais criados pelo choque de placas litosféricas ao longo de zonas de subdu- 
ção, ou ainda ao longo de zonas de colisão de massas conti. nentais. São essencialmente formadas por calhas relacionadas a movimentos cisalhantes (ou wrench) em áreas transtensionais localizadas dentro dos cinturões dobrados que circundam as margens convergentes de alguns continentes. Este tipo é exemplificado pelas bacias de Maracaibo e Gippsland. - Bacias do Tipo VIII (Delta) - São bacias do Terciário Tardio, formadas por deposição de grandes quantidades de sedimentos terrígenos trazidos por grandes rios, como o Níger, Mississípi, Mackenzie, Amazonas, Nilo etc., podendo desenvolver-se em qualquer cenário tec tônico.

No decorrer da década de 70 , alguns autores, a partir de diferentes enfoques, apresentaram outras classificaçōes de bacias. Entre os mais importantes podem ser citados Perrodon (1977), Huff (1978) e Bally \& Snelson (1980) (Quadros $I E$ e $1 F$ ). Nelas também foram consideradas as áreas estáveis (cratônicas), divergentes, convergentes e transcorrentes, dentro do contex to da Tectônica Global.

Bally \& Snelson (1980), com uma visão original da Tectônica de Placas, discutida no excelente artigo Realms of Subsidence, apresentaram sua classificação (Quadro $I F$ ) baseada na presença de zona de subdução típica (tipo B, ou seja, da placa oceânica sob a crosta continental) e na existên. cia de outra zona de subdução, em posição simétrica à primeira, envolvendo a crosta continental, que formariam um par de subduções dando origem a megassuturas. Dentro deste conceito global, Bally \& Snelson reclassificariam os geossinclinais de Kay (1947) e as bacias de Weeks, de Uspens. kaya e de Klemme de modo bastante consistente, separando: $a$. bacias localizadas dentro da litosfera rígida, não associadas à formação de megassuturas; $b_{i}$ bacias associadas à formação de megassuturas compressionais ou bacias perissuturais; $\mathrm{e}$, finalmente, $c$. bacias contidas nestas megassuturas ou bacias epi-suturais, associadas a processos de subdução do tipo B.

Klemme, em 1980, reviu sua classificação estudando mais de 600 bacias ou sub-bacias no mundo inteiro. Mantendo então seus tipos básicos, definidos em 1970, introduziu algumas modificações, comentadas anteriormente, e teceu diversas considerações sobre os métodos correntes de avaliação do potencial petrolífero de bacias. Dentre estes métodos destaca-se a utilização das técnicas de avaliação múltipla, que consideram os fatores fundamentais para a ocorrência de petróleo, isto é, gerador, reservatório, trapa e selante. Neste trabalho, Klemme ressalta o caráter dinâmico das bacias, no contex to da Tectônica de Placas, no qual elas aparecem evoluindo, ao longo do tempo, de uma classe para outra. $O$ autor deixa então transparecer sua crescente preocupação em situar as bacias sedimentares dentro de uma óptica mais evolutiva, e não simplesmente dentro de classes estanques (Fig. 3).

Bois, Bouche \& Pelet (1982), estudando a distribuição das reservas de petróleo desde o Cambriano até o Holoceno, em função de sua situação geotectônica, definiram nove tipos de bacias, em parte baseados em Bally \& Snelson (1980) e Huff (1978).

Klemme (1983), em novo artigo que enfatiza a avaliação do potencial petrolífero das bacias pelo estudo do tamanho dos campos de petróleo nelas contidos, lançou uma nova classificação, em que só cinco tipos englobam seus oito tipos anteriormente definidos. Este novo agrupamento constituiu-se em uma nova tentativa do autor para dar uma lógica genético-evolutiva à sua classificação de bacias.
Perrodon (1983), com enfoque na definição de sistemas petrolíferos em função da Teoria da Tectônica de Placas, definiu duas principais áreas de evolução de bacias (Quadro $l G$ ): o domínio intraplaca e o domínio das margens ativas. $\mathrm{Na}$ primeira categoria, a evolução da bacia se inicia com um estágio de rifteamento que pode evoluir para uma bacia intracratônica ou para uma bacia de margem passiva, incluindo os casos particulares das bacias deltaicas e bacias associadas com movimentos laterais (strike-slip). Na segunda, estão: bacias do tipo cisalhante (shear) ou pull-apart nas áreas de falhas transformantes; bacias de arco (ante-arco, intra-arco e retro-arco) em áreas de convergência, se a subdução ocorre com esforços menos elevados; ou bacias do tipo antefossa nos limites dos cinturōes dobrados, nos casos de subdução com grandes esforços e colisão continental. Segundo o autor, as bacias da segunda categoria, ao contrário das demais, sã̃o instáveis e de pequena duração no tempo geológico.

Na comunidade geológica da Petrobrás, após o uso, durante muitos anos, de uma classificação temporal bastante simplificada (bacias paleozóicas, mesozóicas e cenozóicas), a necessidade de se entender e agrupar geneticamente as bacias sedimentares brasileiras também se manifestou na década de 70 , visando sobretudo qualificar e quantificar, em grandes números, as nossas perspectivas petroliferas. A classificação de Klemme (1970) foi, desta forma, adotada e amplamente utilizada, tanto em relatórios internos como em publicações externas, com destaque para o trabalho pioneiro de Asmus \& Porto (1972). Estes autores enquadraram as bacias brasileiras nos tipos básicos, bem como discutiram particularidades de algumas delas que não haviam sido referidas na classificação original de Klemme (op. cit.). A partir deste trabalho inicial, os sucessivos avanços no conhecimento das bacias brasileiras foram registrados nos trabalhos de Asmus (1975, 1979, 1981), Asmus \& Porto (1980), Asmus \& Guazelli (1981), Asmus \& Ferrari (1978) e Asmus \& Baisch (1982). Ainda, em 1982, Szatmari \& Porto elaboraram nova classificação das bacias sedimentares brasileiras, na qual levaram em consideração diversas bacias terrestres anteriormente não classificadas (Quadro 3).

Em dezembro de 1983, um grupo da Exxon liderado por D.R. Kingston, C.P. Dishroon e P.A. Williams propõe um sistema mais dinâmico de classificação de bacias. Tal sistema é fruto de sua experiência de 15 anos na reconstituição do movimento das placas tectônicas e sua implicação no quadro evolutivo estrutural-estratigráfico nas bacias relacionadas. $\mathrm{O}$ volume de dados disponíveis pela Petrobrás já permite a utilização desta metodologia nas bacias brasileiras.

\section{SISTEMA GLOBAL DE CLASSIFICAÇÃO DE BACIAS (S.G.C.B.) DE KINGSTON ET AL. (1983) - PRINCIPIOS E METODOLOGIA Este sistema surgiu na literatura espe-} cializada basicamente como reflexo da tendência atual em se agrupar as bacias sedimentares segundo uma óptica tectono-sedimentar evolutiva. Este sistema, de carâter fundamentalmente descritivo, constitui, igualmente, uma iniciativa no sentido de atender a uma necessidade crescente de criação de uma linguagem informatizável para os dados geológicos, de grande utilidade, sobretudo na esfera gerencial. Desta forma, na realidade, não se estipula, como tradicionalmente proposto por outras classificações, um rol de tipos de bacias dentro do qual cada bacia estaria inserida. Mais adequado seria considerá-lo como um sistema de codificação pelo qual 


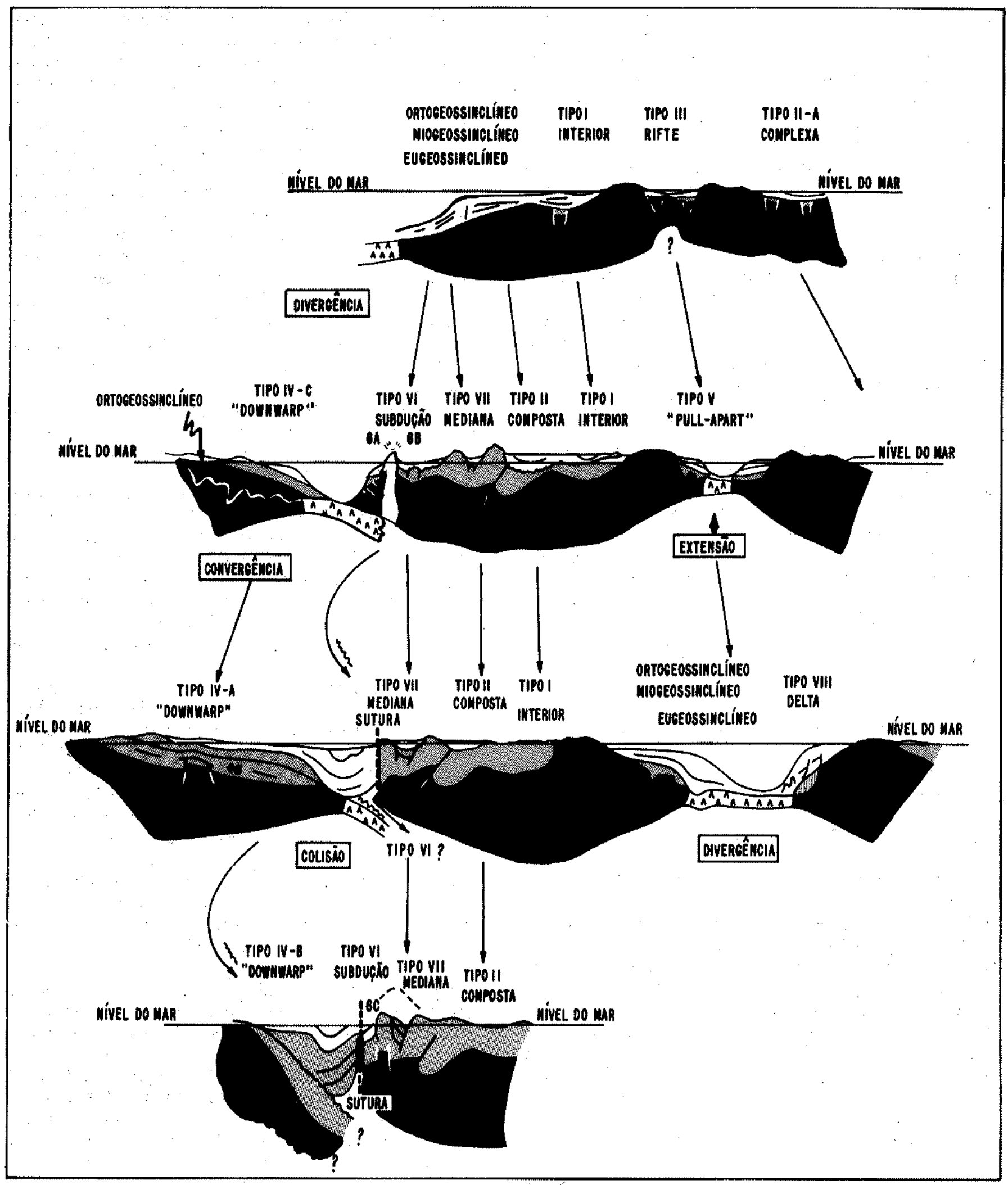

Figura 3-Evolução geotectônica das bacias sedimentares (segundo Klemme 1980) 


\begin{tabular}{|c|c|c|c|}
\hline \multirow[b]{2}{*}{ 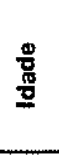 } & \multirow[b]{2}{*}{ Bacia } & \multicolumn{2}{|c|}{ Classificação e Estilo Tectônico } \\
\hline & & $\begin{array}{r}\text { Asmus \& Porto } \\
\text { (1972) - (Termos } \\
\text { do Klemme 1971) } \\
\end{array}$ & $\begin{array}{l}\text { Szatmari \& } \\
\text { Porto (1982) }\end{array}$ \\
\hline \multirow{2}{*}{ 용 } & $\begin{array}{l}\text { Pantanal } \\
\text { Bananal } \\
\end{array}$ & - & $\begin{array}{l}\text { Intracratônica de } \\
\text { interior remoto }\end{array}$ \\
\hline & Paraíba & - & Rifte \\
\hline \multirow[b]{3}{*}{ 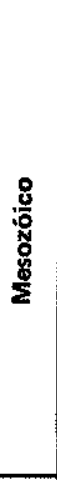 } & Acre & $\|$ & $\begin{array}{l}\text { Intracontinental } \\
\text { cratônica da } \\
\text { antefossa andina }\end{array}$ \\
\hline & $\begin{array}{l}\text { Tacutu } \\
\text { Maraj6 } \\
\text { Recon./Tucano }\end{array}$ & III & $\begin{array}{l}\text { Rifte abandonado } \\
\text { (aulacógeno) }\end{array}$ \\
\hline & \begin{tabular}{|l|} 
Barrelrinhas \\
Potlguar \\
Serglpe/Alagoas \\
Bahia Sul \\
Espirlto Santo \\
Campos \\
Santos \\
Pelotas
\end{tabular} & $111 \cdot V$ & $\begin{array}{l}\text { Rifte evolulndo } \\
\text { para pull apart }\end{array}$ \\
\hline \multirow{2}{*}{ 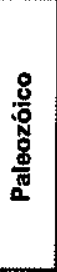 } & $\begin{array}{l}\text { Paraná } \\
\text { Maranhão } \\
\text { Médlo e balxo } \\
\text { amazonas }\end{array}$ & 1 & $\begin{array}{l}\text { Intracratônlcas de } \\
\text { interior remoto. } \\
\text { amplos arcos regionais }\end{array}$ \\
\hline & Alto amazonas & 1 & $\begin{array}{l}\text { Intracratônica de } \\
\text { Interior próximo } \\
\text { - efeltos orogênicos } \\
\text { hercinianos }\end{array}$ \\
\hline 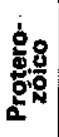 & $\begin{array}{l}\text { Bambuí } \\
\text { (São Francisco) }\end{array}$ & - & $\begin{array}{l}\text { Intracontinental } \\
\text { cratônica da } \\
\text { antefossa } \\
\text { brasiliana }\end{array}$ \\
\hline
\end{tabular}

Quadro 3 - Classificaşão das bacias sedimentares brasileiras segundo Asmus \& Porto (1972) e Szatmari \& Porto (1982)

a cada bacia corresponde uma fórmula-síntese, permanentemente atualizada, cuja elaboração se faz com base nas informações geológicas então disponíveis a seu respeito. Neste artigo, além da codificação propriamente dita, serão apresentadas algumas planilhas representativas nas quais se encontram os elementos fundamentais que deram origem à composição da fórmula-síntese, bem como a coluna sedimentar da bacia considerada. Desta forma, as analogias e comparações, por etapa evolu tiva, se tornam mais evidentes.

A referida composição da fórmula é feita através de códigos alfanuméricos que se reportam a: tectônica formadora da bacia; ciclos e estágios deposicionais; e tectônica modificadora da bacia.

Tectônica formadora da bacia (codificada por letras) A definição de tectônica formadora leva em conta os seguintes fatores (Quadro 4):

- Composição da crosta subjacente, se continental ou oceânica.

- Tipo de movimento que a placa, na qual a bácia está contida, sofreu e que esteja relacionado com a sua formação.
- Posição da bacia na placa.

Resultam, desta forma, nove modelos teóricos e oito modelos práticos de tipos de bacias. Quanto a tectônica formadora, as bacias mais importantes, do ponto de vista de exploração de petróleo, são: Sinéclise Interior (IS), Fratura Interior (IF), Sinéclise de Margem Continental (MS) e Cisalhamento (LL) (Figs. 4A e 4B). Há ainda um tipo misto, também de grande destaque para produção de hidrocarbonetos, cujas evidências para uma origem em Sinéclise de Margem Continental (MS) não são suficientes, já que a bacia foi parcialmente destruída por um cinturão orogenético marginal. Este tipo é denominado Sinéclise de Margem Continental-Sinéclise Interior (MSIS).

Ciclos e estágios deposicionais (codificados por números) Neste caso considera-se, representando um ciclo, os sedimentos e/ou vulcânicas depositados durante um pería. do tectônico. Este pacote de rochas deve ter significado no desenvolvimento da bacia, tanto pela espessura como pela duração no tempo geológico. A subdivisão em estágios, aos quais correspondem precisamente os códigos numéricos, faz-se de acordo com os princípios de análise estratigráfica referentes ao desenvolvimento de cunhas sedimentares transgressivas-regressivas, a seguir descritos (Fig. 5):

- Estágio 1 - Sedimentos de origem não-marinha, geralmente com baixo potencial de geração de hidrocarbonetos (incluem-se sedimentos lacustres oxidados não geradores). Sobre estes sedimentos depositam-se, por transgressão, os sedimentos correspondentes ao Estágio 2.

- Estágio 2. Sedimentos de origem marinha [como definiu Kingston et al. (1983a)] e, também, sedimentos de origem lacustre (estes incluídos pelo grupo da Petrobrás), potencialmente geradores de hidrocarbonetos. $O$ primeiro subgrupo denomina-se $2 \mathrm{M}$ (marinho) e o segundo, 2L (lacus" tre).

- Estágio 3 - Sedimentos continentais regressivos com baixo potencial de geração de hidrocarbonetos. Embora pelo trabalho original de Kingston et al. (1983a) as discordâncias regionais sejam tomadas também como representativas deste estágio, os autores do presente trabalho preferem não considerar esta possibilidade.

Tectônica modificadora da bacia (codificada por letras) Este item, como critério classificatório independente, constitui uma das inovaçōes do sistema proposto por Kingston et al. (1983a). Teoricamente, a tectônica é considerada modificadora quando ela se manifesta apenas afetando o substrato e o pacote sedimentar já formado, não acarretando, portanto, a formação de nova area bacial. Entretanto a distinção entre tectônica formadora e modificadora, na evolução de uma bacia sedimentar, nem sempre pode ser feita com facilidade: A proposição de Kingston et al. (op. cit.) para caracterizar e classificar a tectônica modificadora de uma bacia é feita com base apenas na distribuição espacial e no tipo (critério qualitativo, portanto) de efeito sobre os sedimentos por ela afetados, e não propriamente pela causa. Aqueles autores utilizam-se do termo wrench, sensu latu, referindo-se à estruturação dos sedimentos (em diver* sos graus de intensidade), cuja origem não esteja necessariamente relacionada a cinturões móveis adjacentes, que afetem, lateralmente, toda a seqüência da bacia. Da mesma forma, o termo aqui é aplicado a todas e quaisquer feições estruturais presentes nas áreas baciais, engendradas pelos 


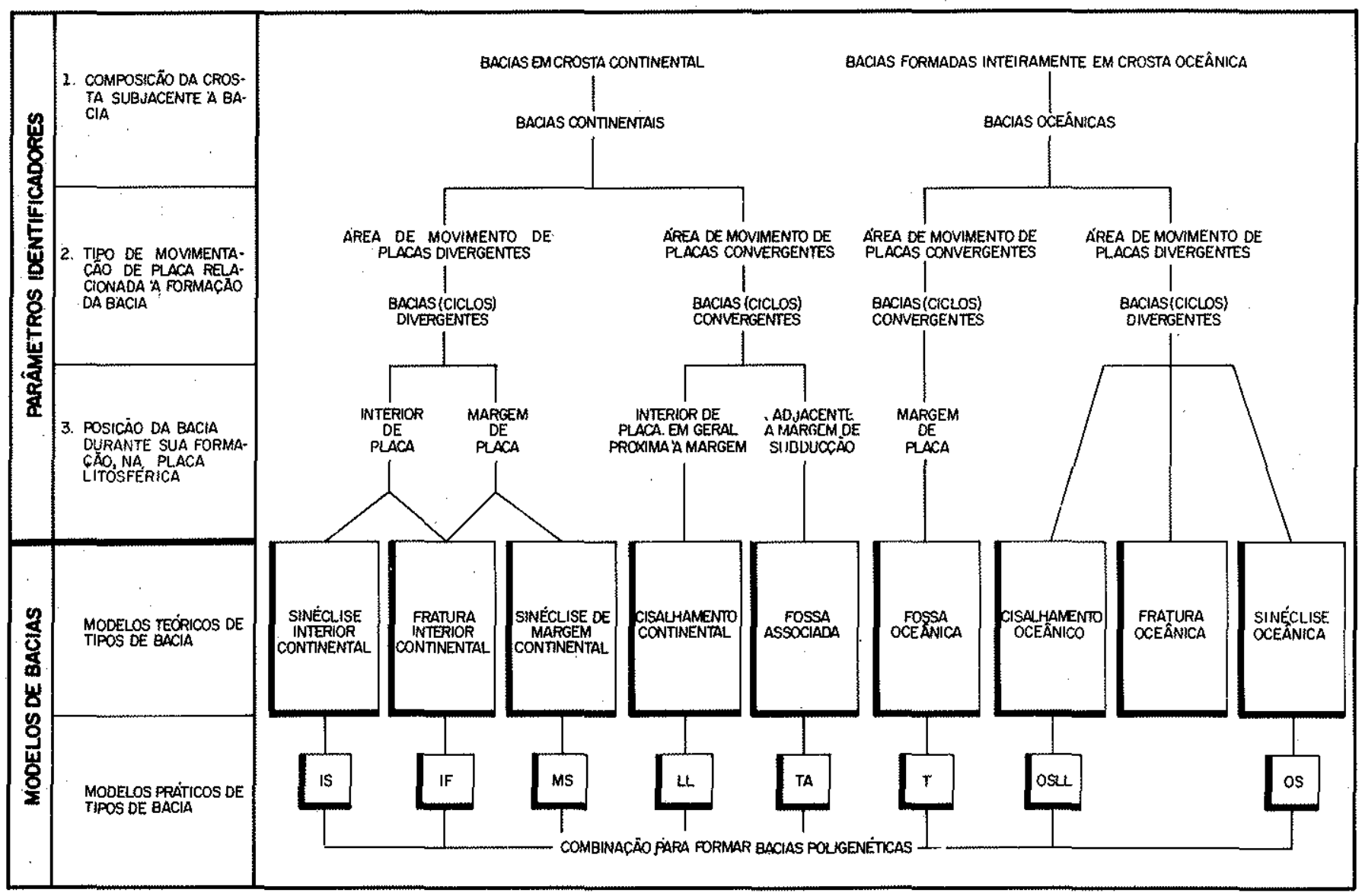

Quadro 4 - Fluxograma de identificação da tectônica formadora das bacias sedimentares. Os códigos terminais seguem a terminologia de Kingston et al. (1983a)

mais diversos esforços, cuja origem estaria relacionada à movimentação das placas litosféricas.

6):

Assim, tem-se três tipos de tectônica modificadora (Fig.

- Cisalhamento (wrench) episódico adjacente ou dentro da bacia (Fig. 6A). $O$ grau de intensidade pode variar de $a$ a $f$, a depender do efeito, ou seja, da(s) feição(ões) tectônica(s) observável(eis).

- Cinturões móveis adjacentes à bacia afetados por cisalhamento (ou wrench). Analogamente, o grau de intensidade pode variar de $a$ a $f$, conforme ilustra a figura $6 B$.

- Cinturões totalmente dobrados, que caracterizam suturas atuais ou passadas de placas convergentes (Fig. 6C). No Fanerozóico brasileiro, esta situação não se encontra representada.

Para a elaboração desta classificação é preciso considerar todas as feições a que acabamos de nos referir, fazendo-se necessária a confecção de: linhas sísmicas regionais, mapas, geológicos regionais e seções geológicas regionais.

Deste conjunto de dados pode-se obter a história geológica da bacia inserida no contexto da Teoria da Tectônica de Placas. Os grandes ciclos deposicionais e as discordâncias regionais devem ser restaurados com a execução de séries de seções estratigráficas evolutivas. Compilando-se todos estes dados, pode-se, então, definir a fórmula da bacia, que a classifica, A figura 7 ilustra o exemplo de classificação de uma bacia da margem sul-atlântica. Observa-se que, nesta figura, Kingston et al. (1983a) compõem a fórmula final a partir do topo para a base da seqüência sedimentar. No presente trabalho, os autores adotam, ao contrário, a fórmula escrita da base para o topo, por julgarem corresponder melhor à ordem natural de deposição da seqüência sedimentar e da evolução tectônica associada.

\section{APLICACĀOO DO S.G.C.B. AS BACIAS BRASILEI-} RAS A aplicação dos conceitos classificatórios de Kingston et al. (1983) às bacias brasileiras foi idealizada em 1984 por Carlos Walter M. Campos, então diretor da Petrobrás, e realizada por um grupo de trabalho. Este grupo, coordenado por A.M.F. de Figueiredo, foi constituído por geólogos e geofísicos da Petrobrás, que exercem atividades de interpretação nas diferentes bacias onde a companhia atua na área de exploração e/ou produção de petróleo.

Deste modo, embora os autores sejam os principais responsáveis pela fórmula final representativa da evolução de cada bacia, ela exprime seu estágio atual de conhecimento 


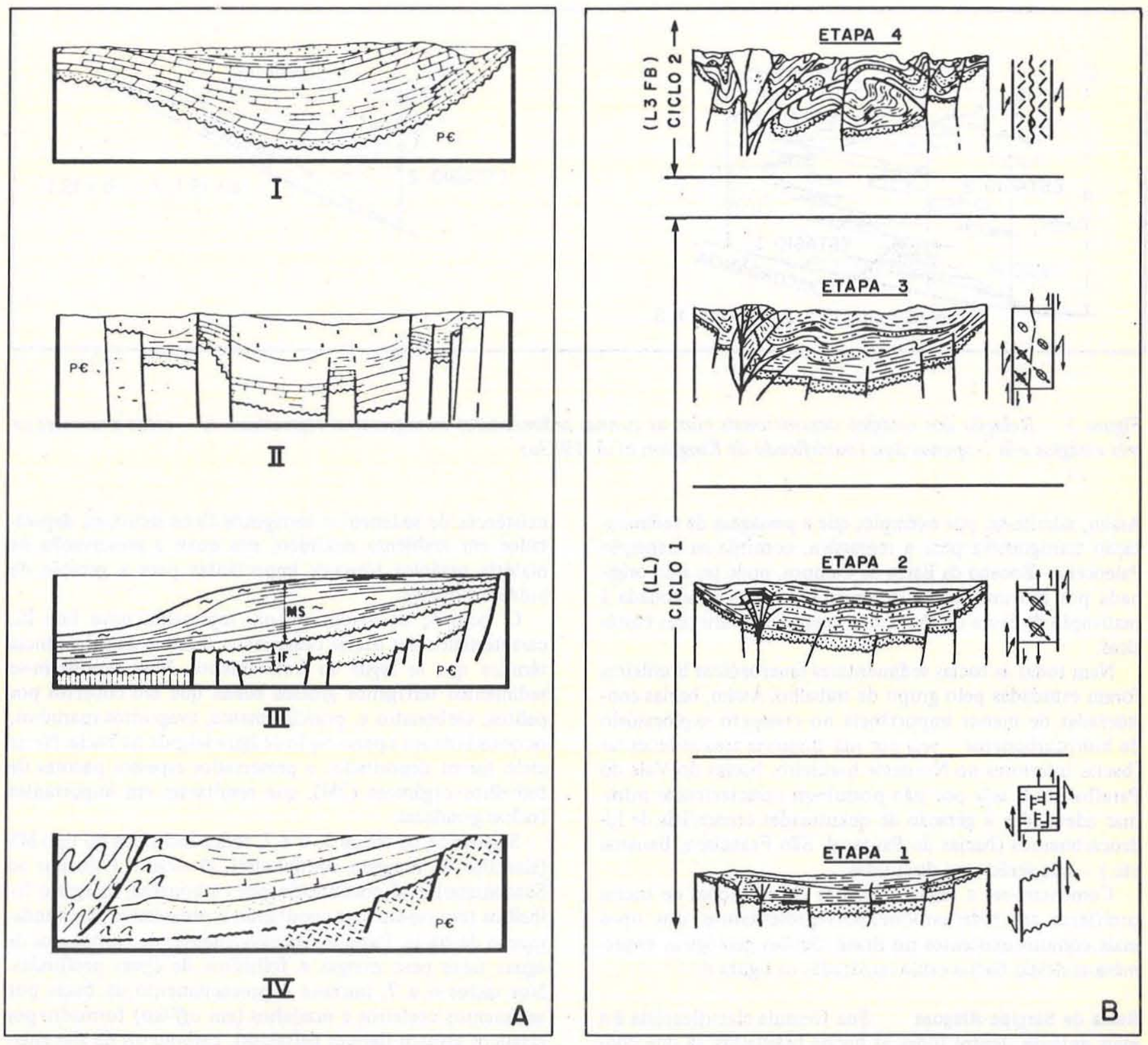

Figura 4 - A. Representação esquemática de tipos de bacias resultantes de diversas tectônicas formadoras (modificado de Kingston et al. 1983a): I - Bacia do tipo Sinéclise Interior (IS); II - Bacia do tipo Fratura Interior (IF); III - Bacia do tipo Sinéclise de Margem Continental (MS); IV - Bacia do tipo Sinéclise de Margem Continental/Sinéclise Interior (MSIS). B. Representação esquemática da evolução de bacias de cisalhamento (LL - wrench). Etapa 1: A bacia se forma por esforços cisalhantes em regime transtensional. Etapa 2: Subsidência da bacia, com o aparecimento de esforços transpressivos. Etapa 3: Incremento dos esforços transpressivos provocando soerguimento e erosão. Etapa 4: Paroxismo do cisalhamento, podendo resultar na destruição da bacia através da formação de cinturões dobrados (L3FB) (adaptado de Kingston et al. 1983a)

geológico. Evidentemente, em algumas delas foram consideradas hipóteses alternativas e, principalmente para aquelas sobre as quais a quantidade de dados disponíveis é pequena (como as bacias do Acre e Tacutu), a fórmula apresentada deve ser tida como preliminar.

Como já se referiu anteriormente, uma das maiores dificuldades encontradas na utilização da classificação residiu na definição das tectônicas (formada e/ou modificada) atuantes na bacia. Obviamente, caso elas não sejam bem avaliadas, podem gerar fómulas totalmente diferentes.

Chama-se a atenção de que este sistema classificatório enfatiza um caráter tectônico controlador dos ciclos sedimentares, que poderiam ter outras origens, tais como variações globais do nível do mar, principalmente no Terciário. 

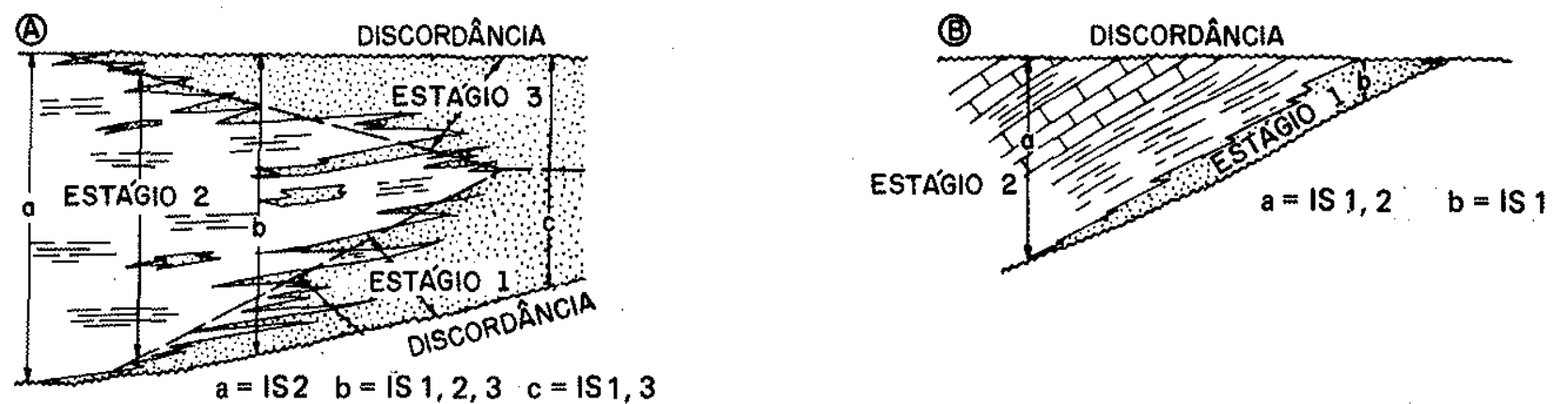

Figura 5 - Relaçăo dos estágios deposicionais com as cunhas sedimentares transgressivas-regressivas. A - estäo presentes os três estágios e B - apenas dois (modificado de Kingston et al. 1983a)

Assim, admite-se, por exemplo, que a passagem da sedimentação transgressiva para a regressiva, ocorrida na transição Paleoceno-Eoceno da Bacia de Campos, pode ter sido originada por movimentação tectônica intraplaca relacionada à reativação da Serra do Mar e não apenas por variações eustáticas.

Nem todas as bacias sedimentares fanerozóicas brasileiras foram estudadas pelo grupo de trabalho. Assim, bacias consideradas de menor importância no contexto exploratório de hidrocarbonetos - seja por sua diminuta área sedimentar (bacias interiores no Nordeste brasileiro, bacias do Vale do Paraíba etc.), seja por não possuírem características mínimas adequadas à geração de quantidades comerciais de hidrocarbonetos (bacias do Pantanal, São Francisco, Bananal etc.) - não serão aqui discutidas.

Comentam-se, a seguir, algumas classificações de bacias proliferas em hidrocarbonetos, representativas dos tipos mais comuns existentes no Brasil. Seções geológicas esquemáticas destas bacias estão mostradas na figura 8 .

Bacia de Sergipe-Alagoas Sua fórmula classificatória é a mais extensa dentre todas as bacias brasileiras, já que contém todas as fases e ciclos possíveis na evolução de nossas bacias costeiras (Quadro 5).

O ciclo I(IS) representa a sedimentação clástica de bacia interlor (flúvio-glácio-marinha) implantada no fim do Paleozóico. Discordantemente sobre este pacote foram depositados os sedimentos continentais lacustres, jurássicos, em bacia interior (IS) que antecedeu à abertura do Rifte Sul-Atlântico. Alguns intérpretes preferem considerar esta etapa evolu tiva como a fase inicial de um ciclo IF devido a sua gênese relacionada ao estiramento crustal. No entanto, a inexistência de falhamentos expressivos neste período deposicional caracteriza uma tectônica formadora do tipo IS.

No Cretáceo Inferior (Berrisiano ao Barremiano), o ciclo 3 está constituído pela fase rifte formada por sedimentos flúvio-del taico-lacustres preenchendo meio-grábens. Nestes lagos tectônicos desenvolvem-se estágios $1,2 \mathrm{~L}$ e 3 , em que a notação $2 L$ tem o significado de demonstrar claramente a existência de sedimentos terrígenos finos lacustres, depositados em ambiente euxínico, nos quais a preservação da matéria orgânica torna-os importantes para a geração de hidrocarbonetos.

O ciclo 4, de idade aptiana, representa nova fase IS, característica das bacias costeiras, e o início da subsidência térmica que se segue ao fraturamento. Nele depositam-se sedimentos terrígenos grossos basais que são cobertos por pelitos, carbonatos e, principalmente, evaporitos marinhos, os quais indicam a penetração de água salgada na bacia. Neste ciclo foram depositados e preservados espessos pacotes de folhelhos orgânicos (2M), que resultaram em importantes rochas geradoras.

Seguem-se os ciclos 5, 6 e 7, todos incluidos no tipo MS (sinéclise de margem continental). $O$ ciclo 5 (Albiano ao Santoniano) está constituído por carbonatos, margas e folhelhos (em on-lap) representando o progressivo aprofundamento da bacia. Passa-se, sucessivamente, de carbonatos de águas rasas para margas e folhelhos de águas profundas. Nos ciclos 6 e 7, inicia-se o preenchimento da bacia por sedimentos costeiros e marinhos (em off-lap) formador por clásticos grossos (leques deltaicos), carbonatos de alta energia (plataforma), margas, folhelhos e arenitos turbidíticos (talude e bacia).

$\mathrm{Na}$ evolução da Bacia de Sergipe-Alagoas, falhas normais foram a expressão mais importante da tectônica formadora durante o ciclo 3. No entanto, durante este ciclo ocorreu uma fase tectônica modificadora (Lc), quando, devido ao ajustamento da bacia às tensões produzidas pelo estiramento crustal e possível rotação diferencial das placas, desenvolveram-se feiçôes estruturais importantes, tais como falhas transcorrentes e dobramentos de grande amplitude, onde significativas quantidades de hidrocarbonetos foram aprisionadas. Alternativamente, esses esforços compressionais podem ser considerados como diretamente relacionados à própria tectônica formadora do ciclo. Nesta hipottese, ele corresponderia à um ciclo LL. Por outro lado, na área alagoana da bacia, existem evidências do desenvolvimento de grandes falhas normais contemporâneas à deposição da seção salife- 


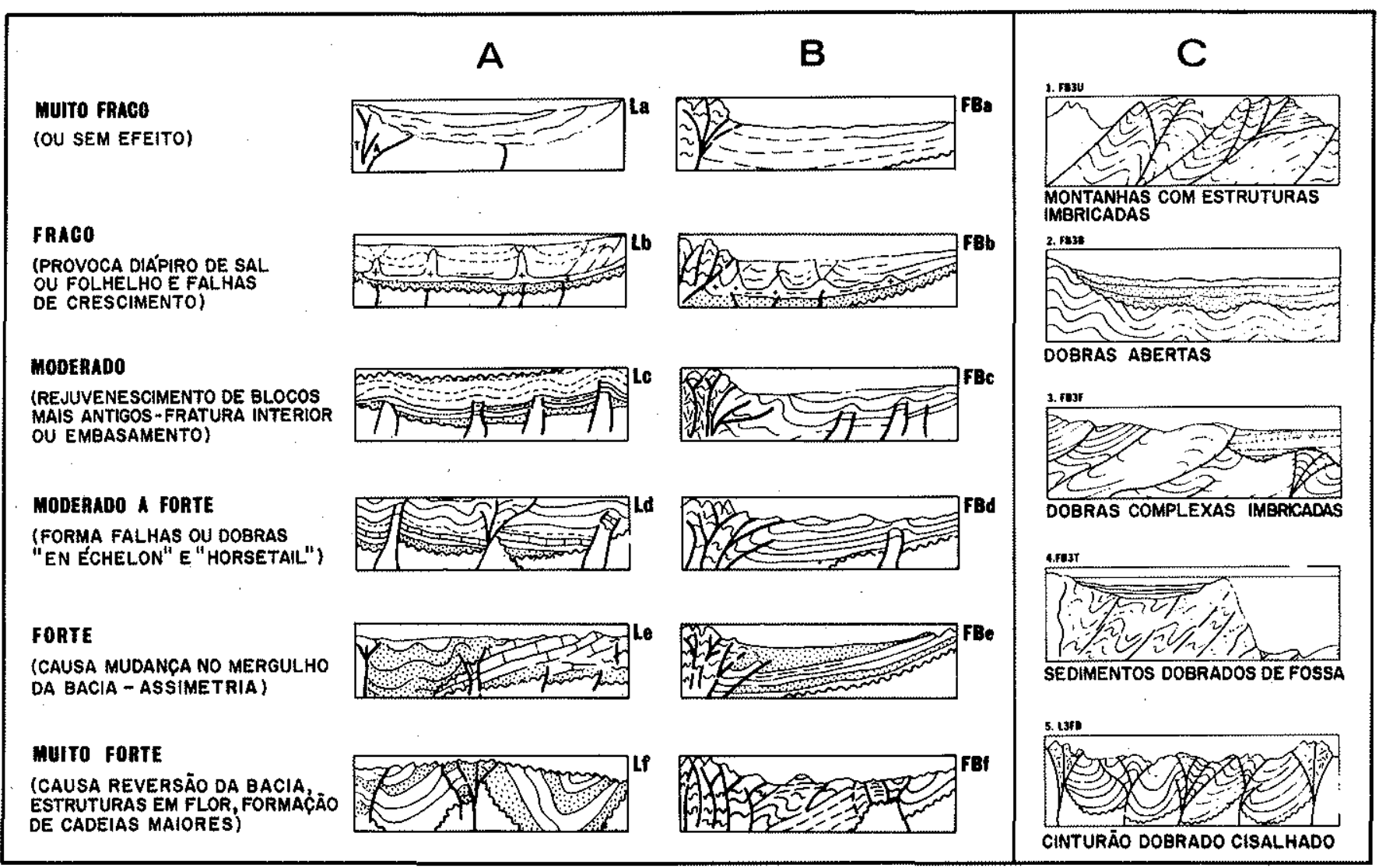

Figura 6 - Representação esquemática dos tipos de tectônica modificadora (os códigos segundo Kingston et al. 1983a): A Eventos de cisalhamento (wrench) episódico na área adjacente à bacia; B - Cinturões móveis adjacentes à bacia e causados por compressão obliqua; $\mathrm{C}$ - Cinturöes móveis afetando a bacia em äreas convergentes

ra (Evaporitos Paripueira), o que caracteriza uma possivel extensão da tectônica formadora IF ou LL ao longo do ciclo 4.

Paralelamente a essas movimentações diastróficas, formaram-se, ainda, importantes feições sinsedimentares, tais como falhas de crescimento afetando a espessa ação sedimen. tar rifte. Já nos ciclos 5 a 7, a seção sedimentar foi também afetada diretamente pela tectônica modificadora (Lb), relacionada à existência de espessa seção de sais solúveis. $\mathbf{O}$ fluxo dessas rochas, altamente plásticas quando submetidas a pressões diferenciais, dão origem a falhamentos lístricos que afetam toda a seção sedimentar sobreposta, podendo evoluir para a formação de almofadas, domos e estruturas de colapso (casco de tartaruga), importantes no armadilhamento de grandes reservas de petróleo.

Bacia do Recôncavo Esta bacia teve um desenvolvimento estrutural-estratigráfico inicial similar ao descrito para a Bacia de Sergipe-Alagoas, até o fim do Eocretáceo (Quadro 6). No ciclo 2, localmente desenvolveram-se evaporitos associados aos red beds da Formação Aliança. Sendo, no entanto, um rifte abortado ou aulacógeno, teve sua sedimentação interrompida no Aptiano (este andar já corresponde a uma fase termal $I S$ ) e, posteriormente, só foi submetida a uma pequena incursão marinha no Terciário Médio.

No decorrer dos andares Buracica e Jiquiá, a bacia foi afetada por tectônica modificadora do tipo Lc, de natureza extensional e transcorrente, possivelmente responsável pela formação de diápiros de folhelhos que atingem a maior parte da seção rifte. Deste modo, embora represente uma bacia altamente prolffera, toda a sua produçẫo de petróleo está armazenada nos terrígenos das fases IS (pré-rifte) e IF, enquanto as rochas geradoras situam-se tão-somente na fase IF.

Bacia de Campos Difere basicamente da evolução apresentada para a Bacia de Sergipe-Alagoas pela aparente inexistência de uma bacia IS intracratônica paleozóica e, ainda, de uma fase jurássica IS antecedente ao rifte (Quadro 7). Do mesmo modo, sedimentos equivalentes aos andares Rio da Serra e Aratu Inferior não foram perfurados até o momento, mas, por outro lado, as lavas basálticas que formam o assoalho da bacia apresentam datações equivalentes a estes andares, devendo ser contemporâneas aos derrames Serra Geral da Bacia do Paraná.

A tectônica modificadora principal da Bacia de Campos estấ representada pela movimentação halocinética (Lb) iniciada no Albo-Cenomaniano que se estende até o Recente. 


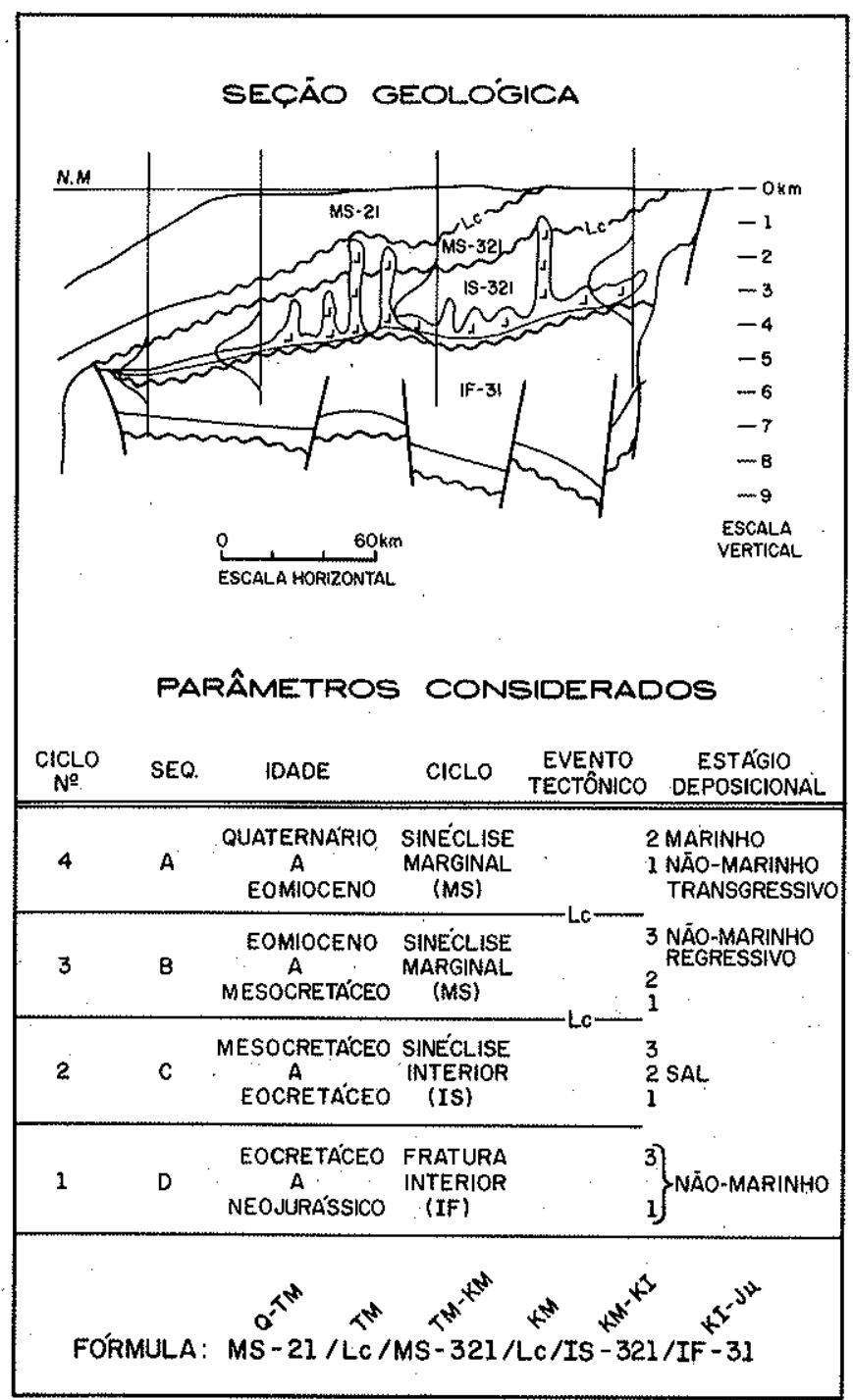

Figura 7 - Exemplo de classificação de bacia da margem sul-atlântica, pelos critérios originais de Kingston et al. (1983a)

Na passagem Paleoceno-Eoceno, ocorreu importante episódio de reativação $(\mathrm{Lc})$, ao qual estão associadas falhas normais e transcorrentes, possivelmente relacionadas a pulsos tectônicos da Serra do Mar e à implantação das bacias terciárias do Vale do Parába.

Aparentemente, a existência de grandes volumes de hidrocarbonetos na Bacia de Campos; emr relação a outras bacias costeiras que lhe são, em teoria, similares, está diretamente ligada à otimização do trinồmio geração-estruturação-reservatorió. A maior parte dos hidrocarbonetos está armazenada nos reservatórios dos ciclos MS, embora o gerador esteja localizado no ciclo IF, que indica terem sido os processos de migração e acumulação de hidrocarbonetos altamente eficientes. torial brasileira, pode representar em sua evolução tectono-sedimentar, diversas bacias desta área (Quadro 8). Ela difere fundamentalmente daquelas da costa leste e nordeste (até a sub-bacia de Mundaú) em sua tectônica formadora estabelecida no Eocretáceo Tardio (Aptiano), estando relacionada principalmente a esforços transcorrentes gerados pelo deslizamento lateral das placas litosféricas. Neste contex to geodinâmico, ăreas transtensionais geram bacias do tipo LL, que contrastam, em vários aspectos, com as bacias do tipo IF das áreas predominantemente divergentes (compare as figuras 4A II e 4B).

Deste modo, sobre uma bacia paleozóica e juro-triássica (Bacia do Parnaíba ou Maranhão), que se estendia pelos continentes sul-americano e norte-africano, até então unidos (ciclos 1,2 e 3 do tipo IS), estabeleceu-se a bacia aptiana de Barreirinhas, como uma fossa pull-apart. Esta bacia foi rapidamente preenchida (ciclo 4) por espessa seção sedimentar essencialmente terrígena flúvio-deltaica (Grupo Canárias). Paralelamente à extensão crustal produzida por esforços transtensionais que geraram tanto falhas normais como falhas de deslizamento horizontal, intensa atividade argilocinética atuava como elemento importante na definição de sua geometria. Esta bacia foi gradualmente invadida pela água do mar, possivelmente proveniente do Atlântico Norte, possibilitando, durante o Albiano (ciclo 5), o afogamento da área e a instalação de espessa plataforma carbonática (Grupo Caju), típica de uma tectônica do tipo MS. No entanto, os principais falhamentos normais, com possíveis componentes transcorrentes, continuaram extremamente ativos controlando as fácies carbonáticas e impondo um estilo tectônico bastante diferente do observado no ciclo MS equivalente na costa leste-nordeste. Nestas bacias, este ciclo é caracterizado pela atuação de tectônica modificadora $(\mathrm{Lb})$ responsável pela movimentação salífera, ausente na Bacia de Barreirinhas. No fim do Albiano, e estendendo-se pelo Cretáceo Superior, na porção leste da bacia ocorreram importantes movimentos transpressionais que criaram enormes estruturas anticlinais (possivel tectônica modificadora Lc).

Sobre a seção do Grupo Caju, desenvolveram-se outras fases MS (ciclos 6 e 7) tipicamente regressivas, similares às descritas para as demais bacias costeiras, onde são comuns os escorregamentos e as falhas lístricas. No entanto, os grandes elementos estruturais da bacia permaneceram ativos até o Neoterciário.

Bacia do Alto Amazonas No interior do continente brasileiro, cercadas por rochas pré-cambrianas do Escudo Brasileiro, ocorrem imensas bacias, tais como as do Paraná, do Parnaíba ou Maranhão e do Amazonas (Quadro 9). Todas elas, em maior ou menor grau, embora pareçam, em uma primeira e rápida análise, geologicamente bastante simples, foram afetadas por diversos ciclos tectônicos de alguma forma ligados à evolução e movimentação das placas litosféricas.

Uma das mais conhecidas e estudadas sub-bacias contidas nestas gigantescas áreas sedimentares paleozóicas é a do Alto Amazonas, onde significativos volumes de gás foram descobertos. Nesta bacia podem ser definidos oito ciclos IS separados por discordâncias regionais. A origem desta sub-bacia continua sendo extremamente discutível e não entraremos no mérito da questão. Os ciclos IS suporpõem-se desde o Ordoviciano, instalando-se sobre uma bacia pré-cambriana possivelmente do tipo IF (ciclo 1). Em resposta às oscila- 


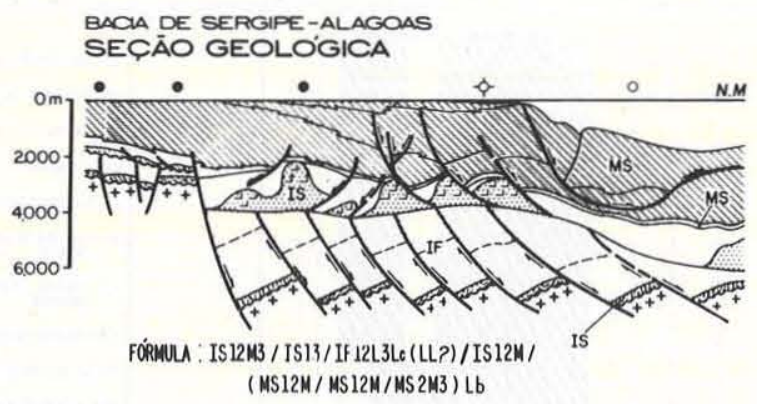

BACIA DO RECÔNCAVO SEÇĀO GEOLÓGICA

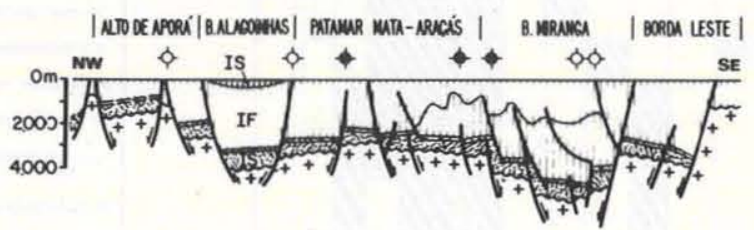

FÓRMUA : IS12M3 / IS13 /IF12L3Le/IS12L3/MS12M

BACIA DE BARREIRINHAS SEÇĀO GEOLO'GICA

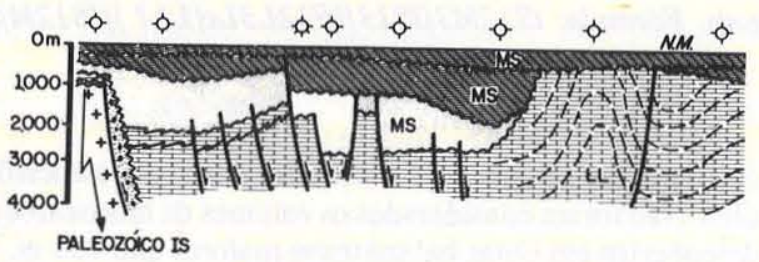

FORMULA : IS12M3 / IS13 /IS12M3 /LL12LLI3/ (MS12M / MS2N3 / MS2M3)L。
BACIA DE CAMPOS

SEÇĀO GEOLÓGICA

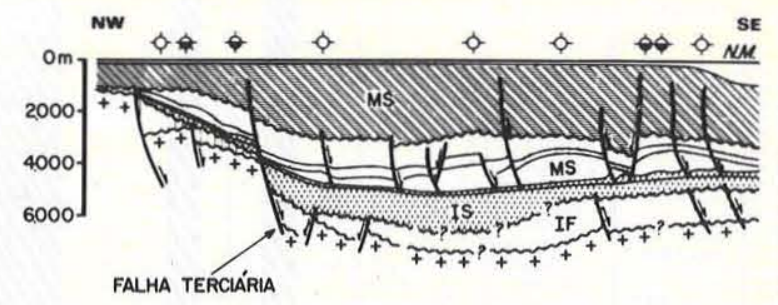

FÓRMULA: IF 12L / IS12M / (MS12M / Lo / MS2M3)L。

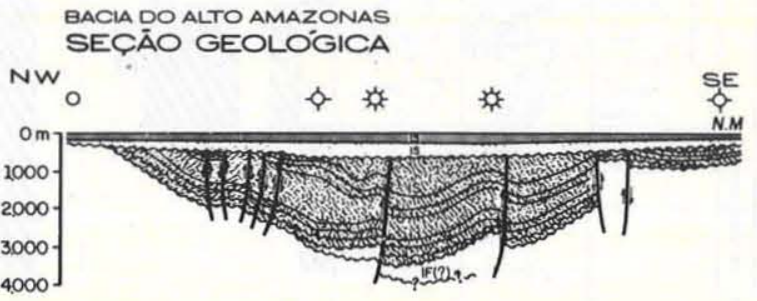

FOORMULA: IF(?) I2M / IS 12 M3 / ISI/ IS I2M3 / IS I2M3 / IS I3/Ld/ IS I3 / ISI3

Figura 8 - Seções geológicas esquemáticas das bacias de Sergipe-Alagoas, Recôncavo, Campos, Barreirinhas e Alto Amazonas, destacando seus ciclos evolutivos, de acordo com a classificação de Kingston et al. (1983a)

ções da placa litosférica estabeleceram-se sucessivas fases de sedimentação marinha epicontinental, que se alternaram com períodos erosivos. A partir do Neocarbonífero (ciclo 5), a bacia tornou-se restrita, possivelmente pelo início da elevação dos Andes e nela, em decorrência de clima extremamente árido, foram depositados espessos pacotes de evaporitos (anidrita e sais solúveis). No Jurássico, ocorreu movimentação tectônica modificadora importante (seja ligada à abertura do Atlântico Norte e do Golfo do México, seja à zona de subdução andina), que resultou na introdução de sills e diques de diabásio (fase tensional) e, posteriormente, na formação de grandes falhas transcorrentes ao longo do eixo da bacia com dobramentos e falhamentos reversos arranjados en échelon (fase compressional). No Neocretáceo e no Terciário, espessos ciclos ( 7 e 8 ) eminentemente terrígenos, derivados da erosão da cadeia andina em processo de intenso soerguimento, recobriram a bacia paleozóica.

Deste mesmo modo, podem ser descritas, por fórmulas similares, todas as demais bacias brasileiras, como é mostrado, sumariamente, na figura 9 e no quadro 10. Este quadro permite também a análise, paralelamente a história geológica de todas as bacias, podendo-se assim estabelecerem-se analogias e diferenças no contexto evolutivo geotectônico de cada uma delas.

\section{OCORRÊNCIA DE HIDROCARBONETOS (RESERVAS) NAS DIVERSAS CATEGORIAS DE BACIAS DO S.G.C.B.} Panorama Mundial $\mathrm{O}$ mesmo princípio de análise múltipla na avaliação do potencial petrolífero, já utilizado por diversos outros autores (especialmente Klemme 1970 e 1980), pode, igualmente, ser aplicado através do sistema proposto por Kingston et al. (1983a). Entre os diversos fato- 


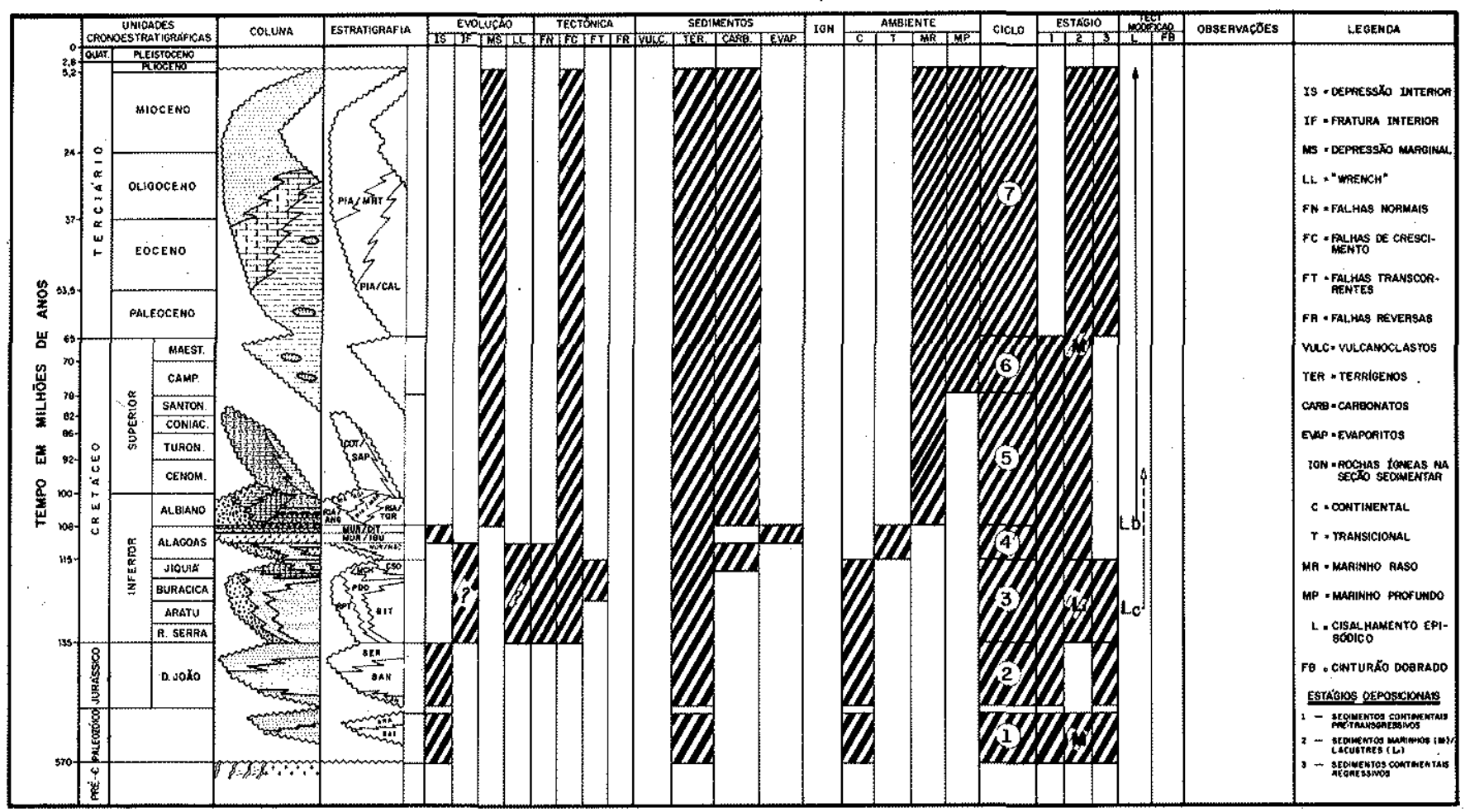

Quadro 5 - Classificação proposta para a Bacia de Sergipe-Alagoas. Fórmula: IS12M3/IS13/IF12L3Lc(LL? )/IS12M/(MS $12 M / M S 12 M / M S 2 M 3) L b$

res e/ou combinação de fatores a serem considerados esta. tisticamente, encontra-se a relação imediata: tipo de bacia (tectônica formadora) $x$ reservas de óleo e/ou gás.

Os dados apresentados por Kingston et al. (1983b), no artigo Hydrocarbon Plays and Global Basin Classification, correspondem ao percentual em número de bacias que, por tipo, são produtoras. Transcrevendo-os, temos (considere- \$e, como universo apenas os ciclos estudados pelos autores): - $29 \%$ de todos os ciclos IS produzem hidrocarbonetos comercialmente;

- $36 \%$ de todos os ciclos IF produzem hidrocarbonetos comercialmente;

- $20 \%$ de todos os ciclos $M S$ produzem hidrocarbonetos comercialmente (Obs.: dos 60 deltas terciários conhecidos apenas quatro produzem comercialmente; e aqueles autores consideram a maioria dos ciclos MS como de risco elevado);

- $47 \%$ de todos os ciclos $L L$ produzem comercialmente hidrocarbonetos;

- $50 \%$ de todos os ciclos mistos MSIS produzem comercialmente hidrocarbonetos.

Os demais ciclos são considerados, por aqueles autores, de elevado risco exploratório.

Panorama Brasileiro Os dados pertinentes ao Brasil foram extraídos do Relatório de Reservas de Petróleo da Pe trobrás e analisados qualitativa e quantitativamente. Para efeito de estimativa geológica, foi considerado o somatório dos volumes in place de óleo-equivalente $\left(1.000 \mathrm{~m}^{3}\right.$ de gás $=1 \mathrm{~m}^{3}$ de óleo) provado, provável e possível. 0 gás cubado corresponde ao gás não associado e ao gás associado ao óleo. Não foram considerados os volumes de hidrocarbonetos descobertos em cotas batimétricas maiores que $400 \mathrm{~m}$.

Do ponto de vista de rochas-reservatório, a maior parte dos hidrocarbonetos descobertos até o presente se concentra em quatro bacias (Campos, Recôncavo, Sergipe-Alagoas e Potiguar), e nos ciclos IS, IF e MS, conforme mostra o quadro 11. Estas rochas-reservatório compreendem, essencialmente, arenitos distribuídos na faixa entre 500 e $3.000 \mathrm{~m}$ de profundidade. Os arenitos do ciclo IS, de idade Jurássica, foram depositados predominantemente por processos continentais flúvio-éclicos de grande distribuição lateral, como, por exemplo, aqueles das Formações Sergi e Serraria das bacias do Recôncavo e Sergipe-Alagoas, respectivamente. Os arenitos do ciclo IF, do Cretáceo Inferior, foram depositados em ambientes lacustres (sistemas flúvio-deltaicos e de leques sublacustres) apresentando menor continuidade lateral.

Já os reservatórios dos ciclos MS são constituídos principalmente por arenitos turbidíticos de margem continental, depositados em leques submarinos de extensão variável. $\mathrm{Na}$ Bacia de Campos, estes leques podem atingir áreas da ordem de centenas de quilômetros quadrados e idades variáveis do Eocretáceo ao Mioceno.

Secundariamente, reservatórios carbonáticos, seja contidos no ciclo MS do Albo/Cenomaniano na forma de barras e oólitos/oncolitos, seja contidos no ciclo IF do Cretáceo Inferior, na forma bancos de coquinas, contêm importantes reservas de hidrocarbonetos, principalmente na Bacia de 


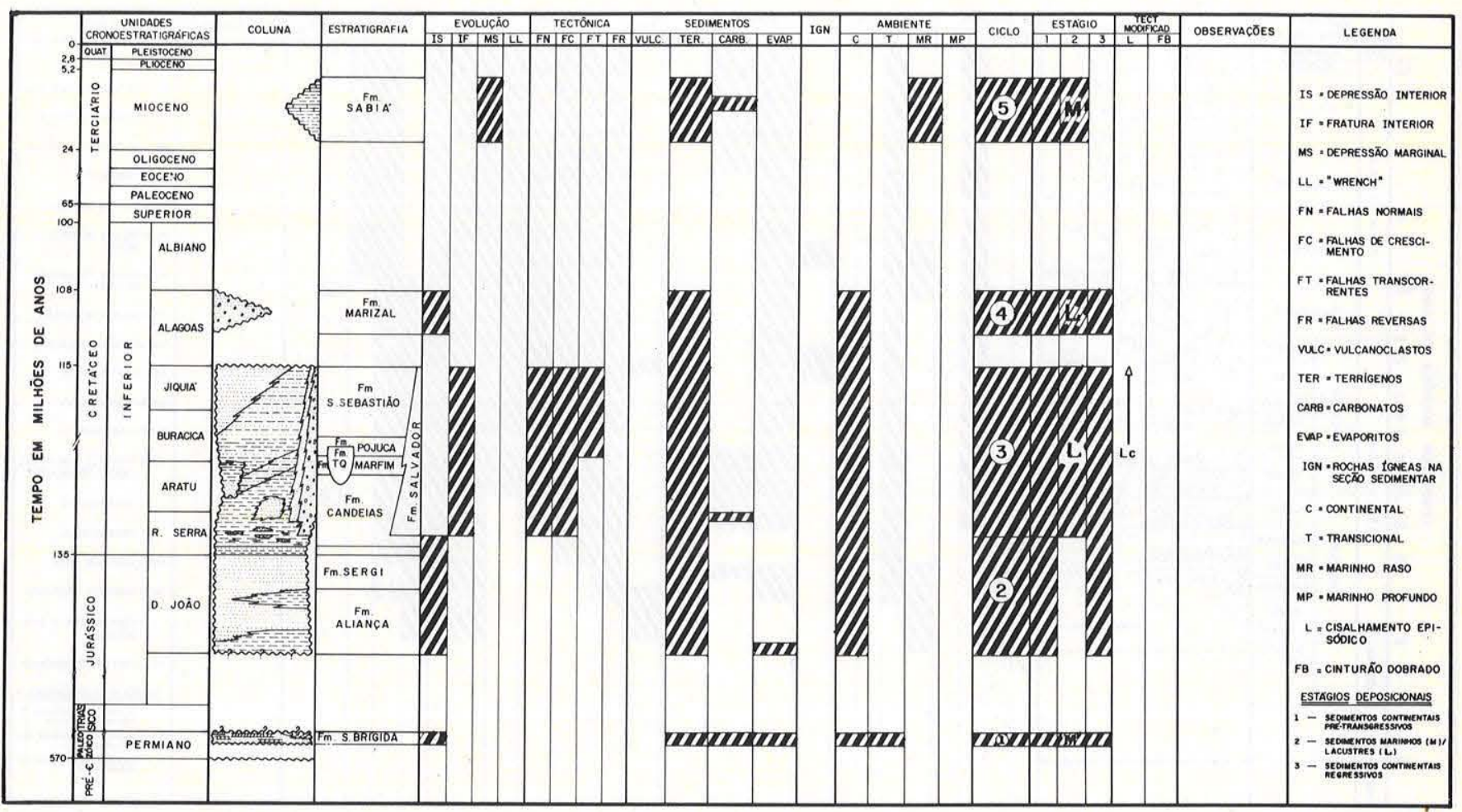

Quadro 6 - Classificação proposta para a Bacia do Recôncavo. Fórmula: IS12M3/IS13/IF12L3Lc/IS12L3/MS12M

Campos. Outras rochas-reservatório podem, localmente, se tornar importantes, tais como folhelhos fraturados (Campo de Candeias, no Recôncavo), basaltos (Campo de Badejo, na Bacia de Campos) e rochas metamórficas fraturadas (Campo de Carmópolis, na Bacia de Sergipe-Alagoas).

Quanto às rochas geradoras, os estudos geoquímicos têm revelado a presença de duas principais seções pelíticas responsáveis pela geração dos hidrocarbonetos contidos nas bacias brasileiras. Estas rochas, presentes nos ciclos IF e IS, estão, neste último, associadas à seção evaporítica. Por exemplo, na Bacia de Sergipe-Alagoas cerca de $70 \%$ dos hidrocarbonetos, até o momento localizado, foram gerados pelos folhelhos do ciclo IS evaporítico, e o restante, por rochas do ciclo IF. Já nas bacias do Recôncavo e de Campos todos os hidrocarbonetos são provenientes de geradores do ciclo IF.

Para efeito de comparação com os dados fornecidos por Kingston et al. (1983a) acerca do panorama mundial, foram computados no quadro 12 os percentuais dos ciclos tectono-sedimentares produtores de hidrocarbonetos, considerando-se apenas as bacias brasileiras de área estimada superior a $7.500 \mathrm{~km}^{2}$, e que estivessem claramente individualizadas à época dos ciclos considerados. Como pode ser visto, existe um excelente paralelismo entre os números comparativos dos ciclos do tipo IS e IF. A grande discrepância entre os números representativos do ciclo MS pode ser creditada ao avançado estágio exploratório das bacias deste tipo na margem continental atlântica do Brasil em relação às bacias do mesmo tipo em margens semelhantes no resto do mundo. No entanto, a diferença no tipo LL deve estar associada ao nosso relativo pequeno conhecimento sobre este tipo de bacia, bem como ao fato de elas, mundialmente, estarem, na maioria das vezes, relacionadas a contexto geotectônico convergente.

CONCLUSÕES A aplicação da classificação de Kingston et al. (1983a) às bacias brasileiras atende à crescente tendência dos exploracionistas das áreas sedimentares de as entenderem e as sistematizarem dentro de critérios geodinâmicos evolutivos.

Este tipo de classificação permite, entre outros aspectos, codificar os eventos tectônicos e sedimentares por meio de uma fórmula-síntese pela qual os atributos essenciais estão expressos sob a forma de letras e números.

A codificação, à primeira vista complexa, pode ser facilmente transposta para a linguagem de computador, permitindo que se obtenha um banco de dados de fácil acesso e manuseio, eventualmente útil para estudos estatísticos e para decisões gerenciais.

Trata-se de uma classificação descritiva extremamente maleável, à qual novos estudos ou interpretações podem ser rapidamente incorporados e, em alguns casos, levar a modificações substanciais de cada fórmula. Vislumbra-se, até em um futuro próximo, a criação de códigos referentes aos aspectos termomecânicos que estão intimamente associados à evolução das bacias.

De qualquer modo, este sistema permite que grandes grupos, similares aos já definidos por classificações an teriores, sejam igualmente estabelecidos. Tais grupos estão relacionadosà 


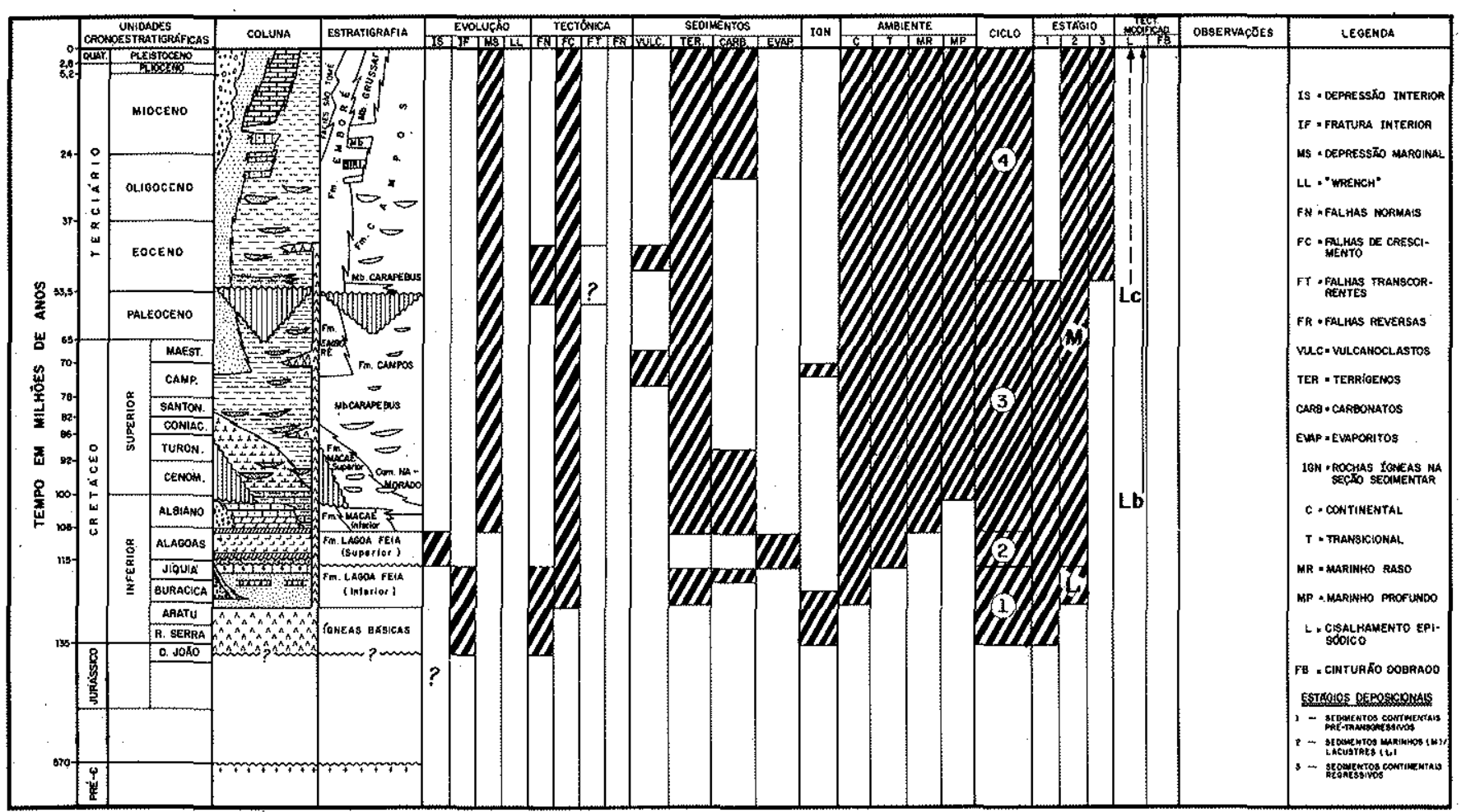

Quadro 7 - Classificaç̃óo proposta para a Bacia de Campos. Fórmula: 1F12L/IS12M/(MS12M/Lc/MS2M3/Lb

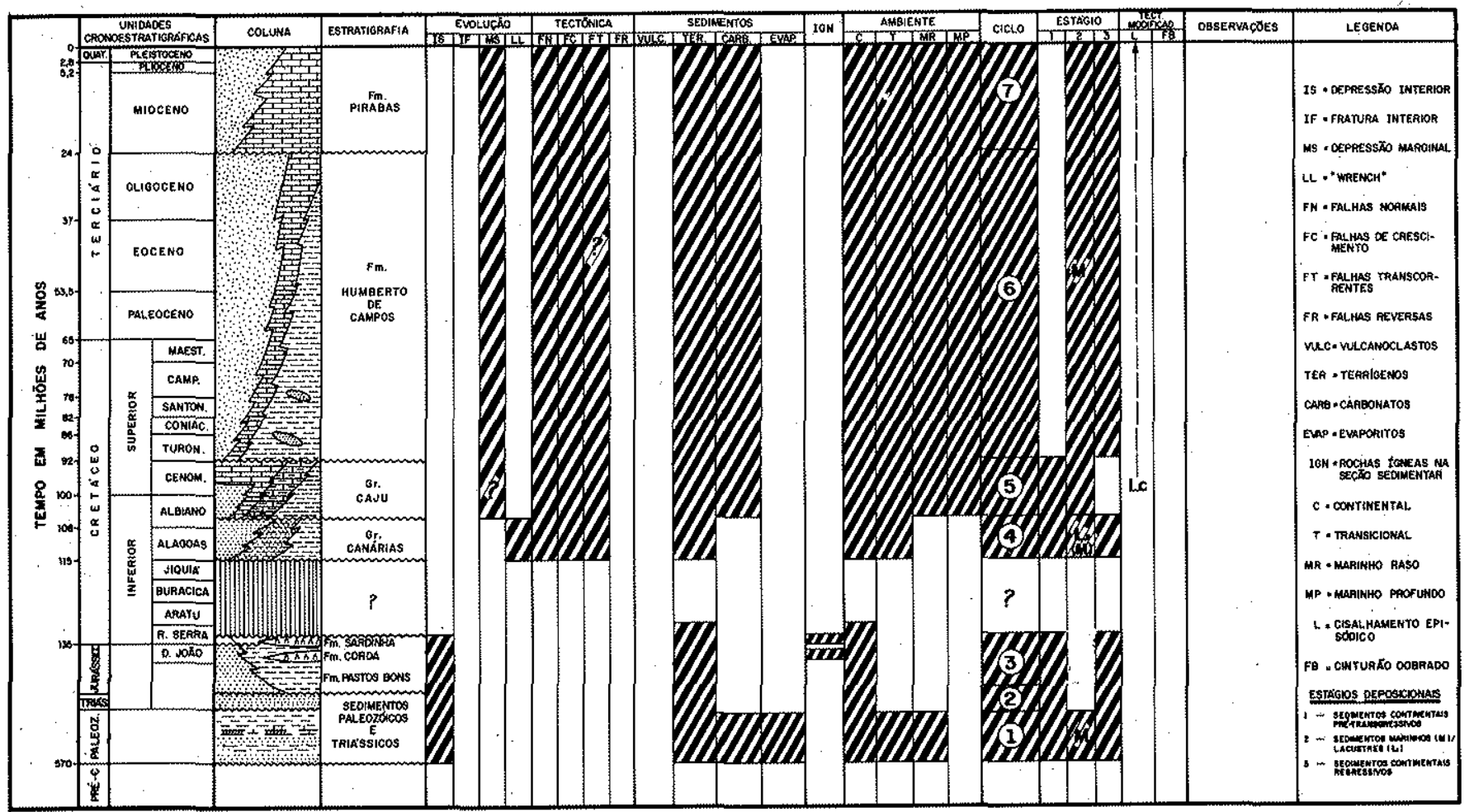

Quadro 8 - Classificação proposta para a Bacia de Barreirinhas. Fórmula: IS12M3/IS13/OS13/LL12LM3/(MS12M/ $M S 2 M 3 / M S 23 / L C$ 


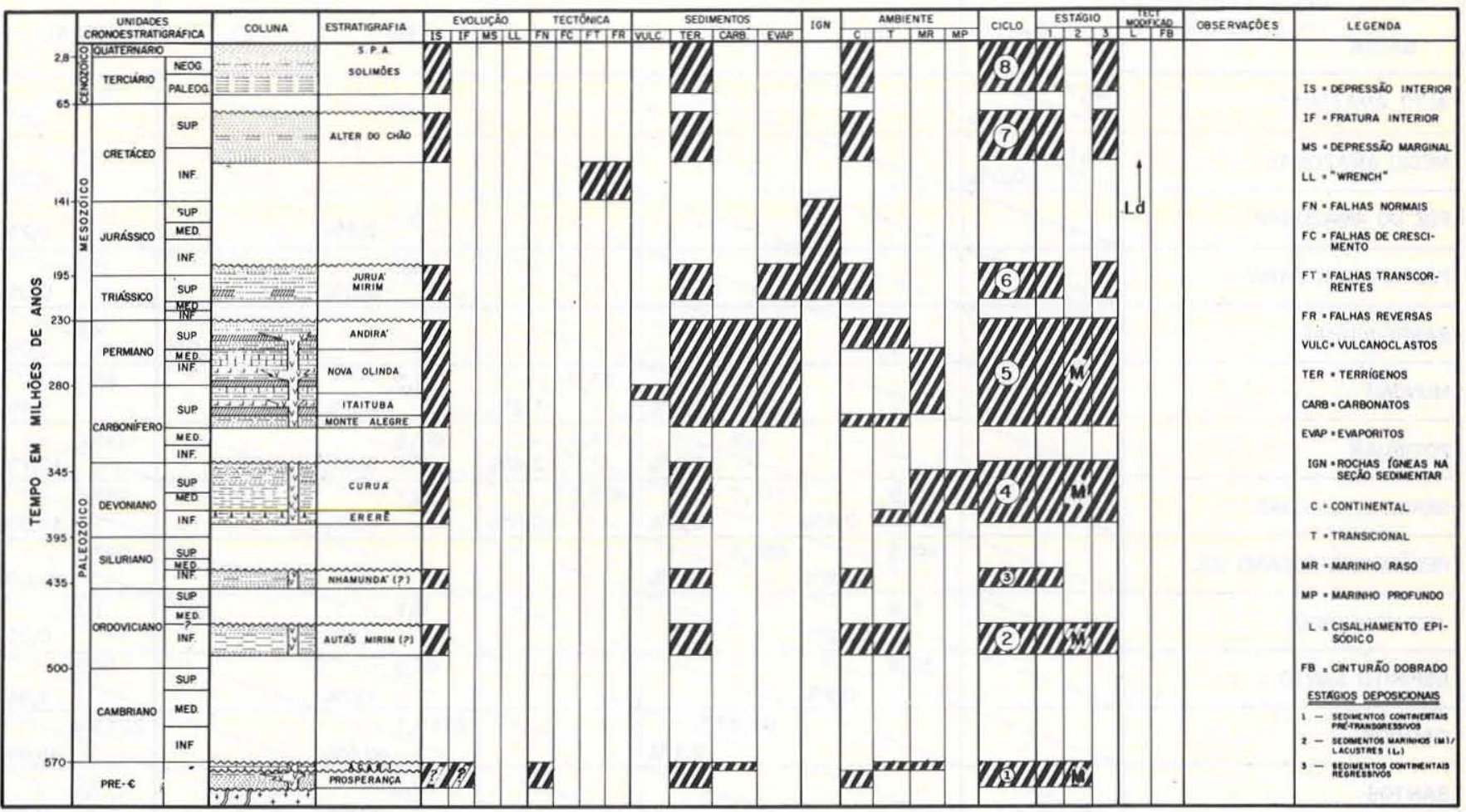

Quadro 9 - Classificação proposta para a Bacia do Alto Amazonas. Fórmula: IF(?)12M/IS12M3/IS1/IS12M3/IS12 M3/IS12M3/IS13/Ld/IS13/IS13

\begin{tabular}{|c|c|c|c|c|c|c|}
\hline \multirow{2}{*}{ BACIAS } & \multirow{2}{*}{$P \in$} & PALEOZOICO & \multicolumn{2}{|r|}{ MESOZÓICO } & CENOZÓICO & \multirow{2}{*}{ FÓRMULA FINAL } \\
\hline & & \begin{tabular}{|l|l|l|l|l|l|} 
CAM & ORO & SIL & OEV & CAR & PER \\
\end{tabular} & TR & \begin{tabular}{l|l|l} 
JUR & $K$ INF \\
\end{tabular} & \begin{tabular}{|l|l|} 
TERC & 0 \\
\end{tabular} & \\
\hline 1 - ACRE & & $\stackrel{\text { NSIS }}{\longrightarrow}$ & & 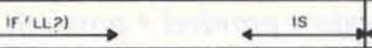 & is & MSIS(?)12M3/IF(Li?)13/FBe/IS13/IS13/FBC \\
\hline 2 - ALTO AMAZONAS & IF (?) & $\stackrel{15}{\longleftrightarrow} \stackrel{15}{\longleftrightarrow}$ & $\leftarrow$ & $\stackrel{\text { is }}{\longleftrightarrow}$ & is & IF(?)12M/ISI2M3/IS1/ISI2M3/IST2M3/ISI3/Ld/ISI3/IS13 \\
\hline 3 -TACUTU & & & & IF (LL?) & 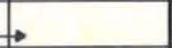 & IF(LL?’2L_?M3Lb/LC \\
\hline 4 - MÉDIO/BAIXO & IF $(?)$ & $\stackrel{\text { Is }}{\longleftrightarrow} \stackrel{\text { Is }}{\longleftrightarrow} \stackrel{\text { Is }}{\longleftarrow}$ & & $\stackrel{15}{\longleftrightarrow}$ & $\longleftarrow$ us & IF(?)/IS12M3/IS12M3/ISI2M3Lb/LC/ISI3/MS1 \\
\hline 5 - MARANÓ & IF (?) & $\stackrel{15}{\longleftrightarrow} \stackrel{15}{\leftrightarrow}$ & & 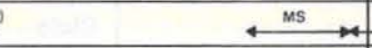 & Ms & IF(?/IS12M3/ISI2M/IF(?) 13/MS12M/MS2M3 \\
\hline $\begin{array}{l}6 \text { - CASSIPORE } \\
7 \text {-FOZDOAMAZONAS } \\
\end{array}$ & & & & IF(LL?)__↔ $\longleftrightarrow$ MS & MS & IF(LL?)12L?M3/LC/MSI2M/(MS12M/MS2M3)Lb \\
\hline $\begin{array}{l}8 \text {-BRAGANCA-VIZEU } \\
9 \text { - SAO LUIS }\end{array}$ & & . & & $\stackrel{\text { IF(น?) }}{\longleftrightarrow}$ & & IF(LL.?) 12M3/LC \\
\hline $\begin{array}{l}\text { 10- PLATAFORMA } \\
\text { PARA-MARANHÃO }\end{array}$ & & & & $\lim _{4 \rightarrow+\infty}^{N 5}$ & Ms & LL12L?M3/MS12MLC/MS2M3Lb \\
\hline 11 - BARREIRINHAS & & $\stackrel{15}{\leftrightarrow}$ & $\stackrel{18}{\longleftarrow}$ & $\operatorname{lims}_{4 \rightarrow \infty}^{M S}$ & $\longrightarrow \stackrel{\mathrm{NS}}{\longleftrightarrow}$ & ISIRM/IS13/IS13/L12LM3/MS12M/MS2M3/MS23)LC \\
\hline 12-PARNAÍBA & & $\stackrel{\text { IF }(?)}{\longrightarrow} \stackrel{15}{\longleftrightarrow} \stackrel{15}{\longleftrightarrow}$ & & 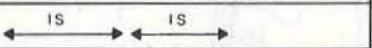 & 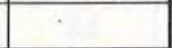 & IF(?)13/IS12M3/IS12M3/(IS12M3/IS13)LC/IS12L3 \\
\hline $\begin{array}{l}\text { 13-PIAUI-CAMOCIM, } \\
\text { ACARAU-ICARAI }\end{array}$ & & & & 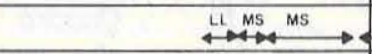 & $\rightarrow$ & LL12LM3/MS12/(MS12M/MS2M3)Lb \\
\hline 14-MUNDAÚ & & & & 4 IF is MS & $\rightarrow$ & IF12L3/IS12M/(MS12M/MS2M3)Lb \\
\hline 15-POTIGUAR & & & & $\stackrel{\text { If }}{\longrightarrow} \underset{4}{\text { IS }}$ MS & $\rightarrow$ & IF12L3LC/IS12M/(MS12M/MS2M3LC)Lb \\
\hline $\begin{array}{l}\text { 16-PERNAMBUCO- } \\
\text { PARAIBA } \\
\end{array}$ & & & & $\stackrel{\text { IF }}{\rightarrow}$ MS & MS & IF(?)13/MS12M/MS2M3Lb(?) \\
\hline 17-SERGIPE-Ai_AGOAS & & $\stackrel{\text { Is }}{\longrightarrow}$ & & 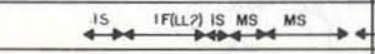 & Ms & 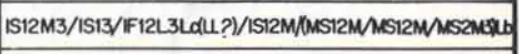 \\
\hline 18-TUCANO-JATOBÁ & & $\stackrel{1 s(?)}{\longleftrightarrow} \stackrel{1 s}{\longleftrightarrow}$ & & $\stackrel{\text { is }}{\leftrightarrow}$ If $\underset{\rightarrow \infty}{\text { is }}$ & & IS13(?)/IS12M3/IS13/IF12L3LC/IS13 \\
\hline 19-RECÔNCAVO & & $\stackrel{15}{\leftrightarrow}$ & & $\stackrel{\text { IS }}{\longrightarrow} \stackrel{1 F}{\rightarrow} \underset{4}{\rightarrow 15}$ & $\stackrel{\text { MS }}{\leftrightarrow}$ & IS12M3/IS13/IF12L3LC/IS12L3/MS12M \\
\hline $\begin{array}{l}20=\text { - BAHIA NORTE - } \\
21=\text { CAMAMU-ALMADA }\end{array}$ & & & & $\stackrel{15}{\longrightarrow} \stackrel{1 F}{\longrightarrow} \stackrel{\text { is }}{\longrightarrow} \stackrel{\mathrm{MS}}{\longrightarrow}$ & & IS13/IF12L3LC/ISI2M/(MSI2M/MS2M3)Lb \\
\hline $\begin{array}{l}22 \text {-JEQUITINHONHA } \\
23 \text { - CUMURUXATIBA }\end{array}$ & & & & 4 If is MS & MS & IF12L3/IS12M/(MS12M/MS2M3)Lb \\
\hline 24-ESPIRITO SANTO & & & & 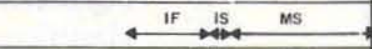 & MS & IF12L3/IS12M/(MS12M/MS2M3)Lb \\
\hline 25-CAMPOS & & & & $4+\frac{115}{4} 12$ & MS & IF12L / IS12M/(MS12M/LC/MS2M3) Lb \\
\hline 26-SANTOS & & & & $4-1$ IS IS MS & Ms & IF12L?3/IS12M/(MS12M/MS12M3/MS12M3)Lb \\
\hline 27-PARANÁ & & $\stackrel{\text { IF }(?)}{\longleftrightarrow} \stackrel{\text { Is }}{\leftrightarrow} \stackrel{15}{\longleftrightarrow}$ & $\rightarrow-\infty$ & is $\rightarrow \stackrel{15}{\rightarrow}$ & & IF(?)FB3B/IS13/IS12M/LC/IS12M3/LC/IS13LC/IS13 \\
\hline 28-PELOTAS & & & & $\stackrel{\text { IF }}{\rightarrow \infty}$ & MS & IF12L?3/IS13/MS12M/MS2M3 \\
\hline
\end{tabular}

Quadro 10 - Sumário de classificação das principais bacias sedimentares brasileiras, segundo critérios adaptados de Kingston et al. (1983a) 


\begin{tabular}{|c|c|c|c|c|c|c|c|}
\hline $\begin{array}{l}\text { CICLO TECTONO - } \\
\text { BACIA }\end{array}$ & is 1 & $\mathrm{Is}_{2}$ & IF & $1 s_{3}$ & MS & LL & TOTAL \\
\hline ALTO AMAZONAS & & & & & & & \\
\hline MÉDIO AMAZONAS & & & & & & & \\
\hline FOZ DO AMAZONAS & & & & & & & \\
\hline PLATAFORMA PARA' & & & & & & & \\
\hline BARREIRINHAS & & & & & & & \\
\hline MUNDAÚ & & & & & & & \\
\hline POTIGUAR & & & & & & & \\
\hline SERGIPE/ALAGOAS & & & & & & & \\
\hline RECÔNCAVO/TUCANO SUL & & & & & & & \\
\hline JEQUITINHONHA & & & & & & & \\
\hline ESPÍRITO SANTO & & & & & & & \\
\hline CAMPOS & & & & & & & \\
\hline SANTOS & & & & & & & \\
\hline TOTAL & 39,8 &, 4 & 2 & 8 & 8,8 & & $\frac{569,8}{100}$ \\
\hline
\end{tabular}

- Inciul reservatórios nos embasamentos cristalinos;

IS-1, sinéclise interior paleozólica

** inclul reservatórios nas rochas vulcânicas; $\theta$

IS-2, sinéclise Interior pré-rifte

** * valor estimado.

is-3, sinéclise interior p6s-rifte

Quadro 11 - Volume de hidrocarbonetos (provado + provável + possivel), nos reservatórios, por bacia e por ciclos correspondentes (em milhões de metros cúbicos de óleo-equivalente e em porcentagem do volume total)

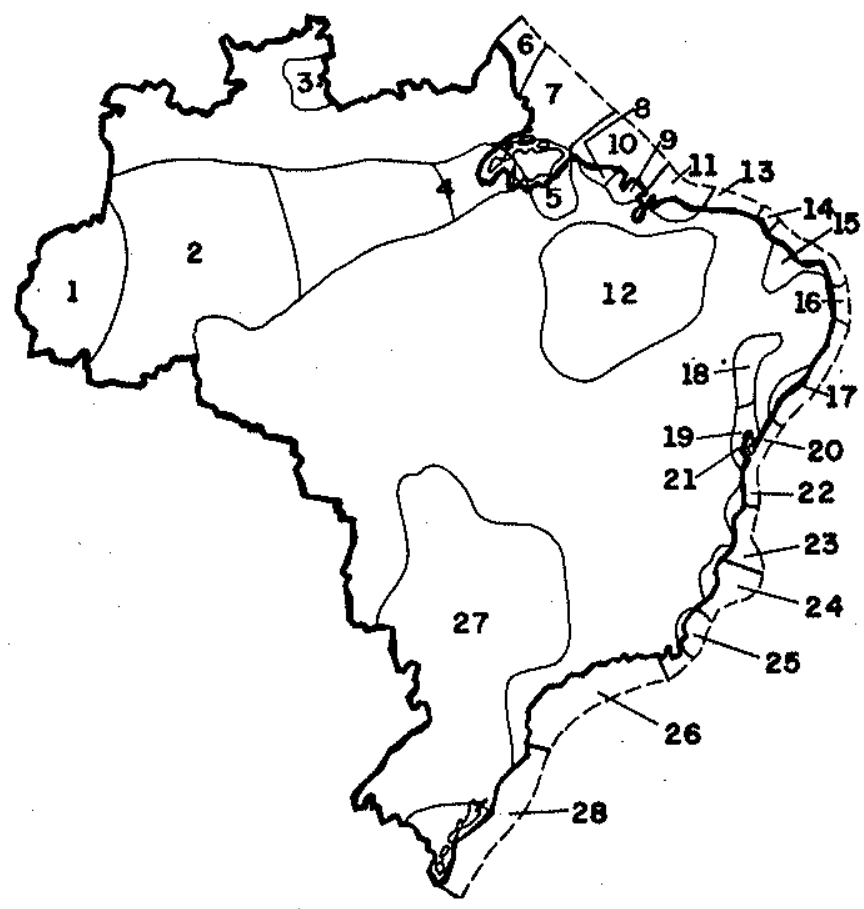

Figura 9 - Localização das bacias sedimentares referidas no quadro 10

\begin{tabular}{|c|c|c|}
\hline $\begin{array}{c}\text { Ciclo } \\
\text { Tectono-Sedimentar }\end{array}$ & $\begin{array}{c}\text { Bacias } \\
\text { Mundiais } \\
\text { Kingston et al. } \\
\text { (1983) }\end{array}$ & $\begin{array}{c}\text { Bacias } \\
\text { Brasileiras } \\
\text { este Trabalho }\end{array}$ \\
\hline IS & $29 \%$ & $26 \%(7 \mathrm{em} \mathrm{27)}$ \\
If & $35 \%$ & $35 \%(7 \mathrm{em} \mathrm{20)}$ \\
MS & $20 \%$ & $53 \%(9 \mathrm{em} \mathrm{17)}$ \\
L & $47 \%$ & $25 \%(1 \mathrm{em} \mathrm{4)}$ \\
\hline
\end{tabular}

Quadro 12 - Quadro comparativo dos percentuais dos ciclos tectono-sedimentares produtores de hidrocarbonetos entre as bacias brasileiras e as do mundo. Entre parênteses, o primeiro número representa quantos ciclos säo produtores e o segundo, o total de ciclos considerados

existência de conjuntos de bacias geradas por diferentes tectônicas formadoras/modificadoras, ligadas ao contex to geotectônico evolutivo da placa sul-americana.

Agradecimentos Integraram o grupo de trabalho que classificou as bacias brasileiras os geólogos Webster U. Mohriak, Dayse Lúcide André, Mário Mendes, José J. Morais Jr., Carlos V. Beltrami, Isaías R. Brasil, Olívio B. da Silva, Mário Vicente Caputo e Luís Felipe S.P. Marques. Colaboraram ainda ativamente, neste trabalho, o geofísico Paulo R. Johann e o geólogo Edson M. Ribeiro, bem como muitos outros colegas do Departamento de Exploração (Depex), aos quais queremos deixar registrados nossos agradecimentos. 


\section{REFERÊNCIAS BIBLIOGRÁFICAS}

ASMUS, H.E. - 1975 - Controle estrutural da deposição mesozóica nas bacias da margem continental brasileira. Rev. Bras. Geoc., 5(3):160-175.

ASMUS, H.E. - 1979 - Conocimiento actual del margen continental brasileño. In: CONGR. LATINOAM. GEOL., 4, Puerto España, 1979. (texto mimeogr. inédito).

ASMUS, H.E. - 1981a - Relacionamento genético das feições geológicas da margem continental sudeste brasileira e da área continental emersa adjacente. In: SIMP. REG. GEOL., 3, Curitiba, 1981. Atas..., Curitiba, SBG/NSP, v. 1, p. 262-273.

ASMUS, H.E. - 1981b - Geologia da margem continental brasileira. In: SCHOBBENHAUS, C. et al., eds. Geologia do Brasil. Texto explicativo do Mapa Geológico do Brasil, escala 1:2.500.000. Brasília, DNPM.

ASMUS, H.E. \& BAISCH, O.R. - 1982 - Dez anos (1972-1982) da classificação das bacias sedimentares brasileiras: críticas e reavaliações. Ciências da Terra, (7):8-12.

ASMUS, H.E. \& FERRARI, A.L. - 1978 - Hipótese sobre a causa do tectonismo cenozóico na região sudeste do Brasil. In: Petrobrás. Aspectos estruturais da margem continental leste e sudeste do Brasil. Rio de Janeiro. CENPES/DINTEP. p. 75-88. (Série Projeto REMAC, 4).

ASMUS, H.E. \& GUAZELLI, W. - 1981 - Descrição sumária das estruturas da margem continental brasileira e das áreas oceânicas e continentais adjacentes - Hipótese sobre o tectonismo causador, e implicações para os prognósticos do potencial de recursos minerais. In: Petrobrás. Estruturas e tectonismo da margem continental brasileira, e suas implicações nos processos sedimentares e na avaliação do potencial de recursos minerais. Rio de Janeiro. CENPES/DINTEP. p. 187-269. (Série Projeto REMAC 2, 9).

ASMUS, H.E. \& PORTO, R. - 1972 - Classificação das bacias brasileiras segundo a tectônica de placas. In: CONGR. BRAS. GEOL., 26, Belém, 1972. Anais..., Belém, SBG, v. 2, p. 67-90.

ASMUS, H.E. \& PORTO, R. - 1980 - Diferenças nos estágios iniciais da evolução da margem continental brasileira: possíveis causas e implicações. In: CONGR. BRAS. GEOL., 31, Camboriú, 1980. Anais..., Camboriú, SBG, v. 1, p. 225-239.

BALLY, A.W. \& SNELSON, S. - 1980 - Realms of subsidence. Can. Soc. Petr. Geol., Mem. n. ${ }^{\circ}$ 6, p. 9-24.

BOIS, C.; BOUCHE, P.; PELET, R. - 1982 - Global geologic history and distribuiton of hydrocarbon reserves. Amer. Asso. Petr. Geol. Bull., 66(9):1248-1270.

DANA, J.D. - 1866 - Observations on the origin of some of the earth's features. Am. J. Sci., 2(42):205-211 e 252-253.

DEWEY, J.F. \& BIRD, J.M. - 1970 - Plate tectonics and geosynclines. Tectonoplysics, 10(5/6):625-638.

HALBOUTY, M.T.; KING, R.E.; KLEMME, H.D.; DOTT, R.H.; MEYERHOFF, A.A. - 1970 - World's giant oil and gas fields, geologic factors affecting their formation, and basin clas- sification, Part 2. Amer. Assoc. Petr. Geol., Mem, n. 0 14, p. 502-555.

HALL, J. - 1859 - Description and figures of the organic remains for the Lower Hilderberg Group and the Oriskany Sandstone. Paleont., Geol. Surv. Albany, v. 3, 544 p.

HUFF, K.F. - 1978 - Frontiers of world exploration. Oil \& Gas J., 76(40):214-220.

KAY, M. - 1947 - Geosynclinal nomenclatures and the craton. Am. Assoc. Petr. Geol. Bull., 31(7):1289-1293.

KING, P.B. - 1959 - The evolution of North America. Princeton, University Press, $189 \mathrm{p}$.

KINGSTON, D.R.; DISHROON, C.P.; WILLIAMS, P.A. - 1983a Global basin classification system. Am. Assoc. Petr. Geol. Bull. 67(12):2175-2193

KINGSTON, D.R.; DISHROON, C.P.; WILLIAMS, P.A. - 1983b Hydrocarbon plays and global basin classification. Am. Assoc. Petr. Geol. Bull. 67(12):2194-2198.

KLEMME, H.D. - 1971 - The giants and the super-giants. Part 2: to find a giant, find the right basin. Oil Gas. J., 69(10):103-110.

KLEMME, H.D. - 1980 - Petroleum basins - classification and characteristics. J. Petr. Geol., 3(2):187-207.

KLEMME, H D. - 1983 - Field size distribution related to basin characteristics. Oil \& Gas J., 81(52):168-176.

LOCZY, L. \& LADEIRA, E.A. - 1976 - Geologia estrutural e introdução à geotectônica, São Paulo, Ed. E. Blücher, 528 p.

MITCHELL, A.H. \& READING, H.G. - 1969 -Continental margins, geosynclines and ocean floor spreading, J. Geol., 77(66):629-646.

PERRODON, A. - 1977 - Concepts, modèles et logique des bassins sédimentaires. Bull Centr. Rech. Expl. - Prod. Elf-Aquitaine, 1(1):111-130.

PERRODON, A. - 1983 - Géodynamique des bassins sédimentaires et systèmes pétroliers. Bull. Centr. Rech. Expl. - Prod. Elf-Aquitaine, 7(2):645-676.

SZATMARI, P. \& PORTO, R. - 1982 - Classificação tectônica das bacias sedimentares terrestres do Brasil. Rio de Janeiro: Petrobrás/Cenpes (rel. int. 673-2703).

USPENSKAYA, N.Y. - 1967 - Principles of oil and gas territories subdivisions and classification of oil and gas accumulations. In: WORLD PETR. CONGR., 7, México, 1967.Proc..., New York, Elsevier, v. 2, p. 961-969.

WEEKS, L.G. - 1952 - Factors of sedimentary basin development that control oil ocourrence. Am. Assoc. Petr. Geol. Bull. 36(11):2071-2124.

MANUSCRITO 377

Recebido em 27 de Agosto de 1986 Revisão aceita em 03 de Fevereiro de 1987

Os dados geológicos não podem jamais representar toda a realidade, mas dela podem apenas se aproximar. O método de aproximação difere de um autor para outro. 